\title{
Crisis global, económica, social y ambiental
}

\author{
Araceli Damián*
}

Si tuviera que resumir el siglo Xx, diría que levantó las más grandes esperanzas concebidas jamás por la humanidad, y destruyó toda ilusión e ideales.

YEHUDI MENUHIN

El presente artículo tiene la finalidad de explorar la compleja crisis del sistema capitalista actual retomando diversos ángulos de su manifestación: económica, social y ambiental. El trabajo está dirigido a examinar las crisis del capitalismo actual a partir de la crisis inmobiliaria y financiera de 2008, que fue considerada como la más grave en el ámbito mundial después de la de 1929. Para ello se examinan, en primer término, las explicaciones que desde la teoría marxista y keynesiana se han ofrecido en torno a las crisis económicas propias del capitalismo. En segundo lugar se analizan algunas de las consecuencias de las crisis padecidas en los últimos cincuenta años, sobre todo en relación con los cambios en las relaciones de poder entre capital y trabajo; ello ha producido un deterioro en las condiciones de vida de la mayoria de la población, que se manifiesta en una creciente pobreza, desigualdad, persistencia del hambre y deterioro ambiental en el mundo.

Palabras clave: crisis económica, crisis social, crisis ambiental, desigualdad y pobreza.

Fecha de recepción: 1 de agosto de 2013.

Fecha de aceptación: 22 de julio de 2014.

\section{Economic, Social and Environmental Crisis}

This article seeks to explore the current complex crisis of capitalism by taking up various angles of its manifestation: economic, social and environmental. It seeks to examine the current crisis of capitalism today since the housing and financial crisis of 2008, considered the most serious in the global arena since 1929. To this end, it begins by exploring the explanations provided by Marxist and Keynesian theory of the economic crises inherent in capitalism. Secondly, it discusses some of the consequences of the crises experienced

* Profesora investigadora del Centro de Estudios Demográficos, Urbanos y Ambientales de El Colegio de México. Dirección postal: Camino al Ajusco 20, col. Pedregal de Santa Teresa, C.P. 14200, México, D.F., México. Correo electrónico: <adamian@ colmex.mx>. 
in the past fifty years, especially in relation to the changes in the power relations between capital and labor. This has led to a deterioration in the living conditions of the majority of the population, expressed in increased poverty, inequality, persistent hunger and worldwide environmental degradation.

Key words: economic crisis, social crisis, environmental crisis, inequality and poverty.

\section{Crisis económica global}

El siglo XX se caracterizó por sus constantes convulsiones políticas y sociales: se desataron dos guerras mundiales y sucedieron diversos episodios de genocidios y guerras civiles. Esto contrasta con los enormes avances de la ciencia y con las mejoras en las condiciones de vida de la población. No obstante, en esta vuelta de siglo, como llamó Bolívar Echeverría (2006) al momento histórico actual, tales logros no se viven con gran celebración, sino con preocupación sobre el futuro de la humanidad debido a la creciente desigualdad socioeconómica y al deterioro del medio ambiente, producto del modelo modernizador adoptado en el sistema capitalista de producción.

Durante el tiempo en que hubo escasez de los medios de subsistencia, ésta retiraba el derecho a la vida de las capas más bajas de la población mundial, y las clases dominantes lograban apropiarse del excedente productivo de la fuerza de trabajo haciéndoles creer a las personas que su obediencia y dedicación al trabajo eran necesarias para mantener un pacto mágico con un "Dios salvador". Pero como plantea Echeverría (2006), con la Revolución Industrial dicha escasez fue superada y lo que se vive ahora es una escasez artificial. El control social se logra ahora mediante un discurso fundamentalista sobre los principios del libre mercado, que supuestamente rigen lo económico y lo social; se hace creer a la inmensa mayoría de las personas que "la mano invisible" del mercado lo controla todo, su vida y su destino.

Los gobiernos y las élites mantienen una defensa a ultranza de la modernidad "realmente existente", banalizan lo político y limitan los márgenes de acción de los trabajadores. Esto ha permitido mantener a grandes contingentes de población en condiciones paupérrimas, al tiempo que la riqueza social se concentra en pocas manos. 
"La escasez (artificial) no es la consecuencia de un fracaso del capitalismo, sino todo lo contrario, el resultado de su triunfo", nos dice Bolívar Echeverría (2006: 41).

El aumento desproporcionado de la concentración de la riqueza se acompaña de constantes crisis, las cuales resultan de las formas adoptadas por el capital para sobreponerse a la ley de la tendencia decreciente de la ganancia $(G$ '). Retomando a Marx, Julio Boltvinik (2010: 147) explica esta ley:

como el trabajo vivo es el único creador de valor (y de plusvalía: $P$ ), a medida que la producción se mecaniza, se automatiza, cada trabajador estará dotado de más y mejores medios de producción (trabajo muerto), para lo cual el capitalista tiene que invertir cada vez más una mayor proporción del capital en dichos medios (capital constante: $C$ ) y una menor en trabajo vivo (capital variable: $V$ ), haciendo que aumente la proporción del capital constante en el total $[C /(C+V)]$, a la que Marx llama la composición orgánica del capital $(O)[\ldots]$ La tasa de ganancia $\left[G^{\prime}=P /(C+V)\right]$ crece con el aumento de la tasa de plusvalía $\left(P^{\prime}=P / V\right)$ y disminuye con el aumento de $O$, por lo cual, dada la tendencia de $O$ a aumentar, se desprende la ley citada.

$\mathrm{Al}$ respecto, John Strachey (1939) planteó que si bien la tendencia decreciente de la $G$ ' es un hecho observado y aceptado por los economistas convencionales, sólo Marx pudo explicar que el propósito de la producción capitalista es el aumento del monto absoluto de la ganancia, el cual puede seguir creciendo a pesar de la baja de la tasa de ganancia, $G$. Esto es posible por la existencia del ejército industrial de reserva que, como planteó Marx, presiona los salarios a la baja, lo que permite aumentar $P^{\prime}$ y compensar la tendencia de $O$ a crecer. Además, al crecer la fuerza de trabajo contratada, crece $P$. En periodos de crisis el ejército industrial de reserva toma la forma de desempleo, el cual coexiste al lado del capital ocioso. Strachey considera que la búsqueda para maximizar el volumen y la tasa de ganancia ha llevado a economistas como Robbins y Hayek a proponer la disminución de los salarios en las crisis; receta que continúa siendo aplicada en la actualidad.

Los economistas convencionales aseguran que con la baja en los salarios la demanda de mano de obra tenderá a aumentar, lo que posteriormente provocará un alza en los salarios, y esto supuestamente llevará al equilibrio en el mercado laboral. Strachey, también siguiendo a Marx, plantea que la única forma de aumentar la demanda de mano de obra, y por tanto el incremento en los salarios, es mediante 
la inversión en capital, ${ }^{1}$ pero al producir más máquinas, la demanda de mano de obra crecerá por arriba de la población trabajadora, por lo cual tarde o temprano el capital enfrentará un aumento salarial, y ello hará caer de nuevo las tasas de plusvalía $\left(P^{\prime}\right)$ y de la ganancia $\left(G^{\prime}\right)$. Las nuevas inversiones en capital producirán más bienes, hasta llegar a un punto en el que se genere una crisis de sobreproducción, la cual también contribuirá a la reducción de $G{ }^{2}{ }^{2}$ Para Strachey, el objetivo fundamental de la producción capitalista es el aumento del monto absoluto de la ganancia, pero como el sistema está sujeto a la ley de la tendencia decreciente de la tasa de ganancia, los capitalistas buscan nuevas áreas de explotación por todo el planeta. Sin embargo siempre se llegará al siguiente límite en el cual la nueva inversión resulta en una masa de ganancia menor, porque se deprime $G$ '. Strachey notó de manera acertada que los periodos de auge asociados al alza de los salarios reales siempre terminaban en crisis por la caída en la ganancia, como ha sucedido en la historia reciente.

Las crisis son también generadas debido a que los capitales acrecentados por la plusvalía terminan manteniéndose ociosos al ser atesorados en los bancos, lo que produce una sobreproducción de capital (Boltvinik, 2010: 152). Cuando las crisis inician, surgen disputas entre los capitales nacionales y los internacionales en su búsqueda de las mejores oportunidades: se gestan guerras (que conllevan la destrucción física del capital), se desvaloriza la fuerza de trabajo por el desempleo y caen las acciones; con ello se crean nuevas condiciones para que aumente $G$ '.

Manteniendo en mente la explicación hasta aquí expuesta sobre la forma en que se desarrollan las crisis del capitalismo, tomamos la información sobre las variaciones en la tasa de ganancia ocurridas entre 1869 y 2007 en Estados Unidos (véase la gráfica 1) para ilustrar lo que ha sucedido en los periodos sobresalientes de auge y crisis global. Elegimos ese país debido a que ha dominado la economía capitalista mundial por décadas y las fluctuaciones en su tasa de ganancia muestran las tendencias en el ámbito global. Como se observa en la gráfica 1, aunque la tasa de ganancia presenta periodos de recuperación

1 El monto de la inversión depende de la tasa de interés; cuando ésta es elevada los capitales tienden a realizar inversiones financieras, mientras que con tasas bajas tenderán a invertir en actividades que les permitan obtener una ganancia.

${ }^{2}$ Strachey considera que para Marx el concepto de sobreproducción de capital y de mercancías no está en relación con las necesidades, sino con la generación de ganancias. 
y crisis, en general tiene una tendencia a la baja. De igual forma podemos ubicar periodos de crisis importantes, como la de finales del siglo XIX y la que se vivió en la antesala de la Primera Guerra Mundial.

La severa contracción económica de los años treinta del siglo XX en Estados Unidos representó un parteaguas en el desarrollo del capitalismo: un tercio de la fuerza de trabajo masculina quedó súbitamente desempleada, lo que provocó que amplios sectores de la población quedaran sin un ingreso que garantizara su sobrevivencia. ${ }^{3}$ Economistas como John Strachey y John Maynard Keynes (2006) [1936] basaron sus reflexiones en esta gran crisis, cuyas secuelas económicas coadyuvaron a que se desatara la Segunda Guerra Mundial.

Una vez finalizada esta guerra, los gobiernos de los llamados países desarrollados instrumentaron políticas encaminadas a reactivar la economía y lograr el pleno empleo, basándose en las ideas de Keynes (2006) [1936]. Este autor parte de cuestionar la Ley de Say, la cual plantea que la oferta crea siempre su propia demanda, ya que los ingresos generados y distribuidos permiten adquirir exactamente la producción y que, por lo tanto, la sobreproducción y las crisis son imposibles. Aun cuando la evidencia derrumbaba esta idea, los economistas convencionales rechazaron la existencia misma de las crisis.

Keynes rompió con el pensamiento neoclásico, ${ }^{4}$ observando que lo que puede ser racional para el individuo, es perjudicial para el todo en su conjunto (Patel, 2009: 70). Sostuvo que durante las crisis disminuía la propensión de los empresarios a invertir debido a la baja en las expectativas de obtener ganancia. Además notó que los ricos reaccionan con un deseo de atesorar, y que por lo tanto reducen su consumo. Así, ante la falta de consumo e inversión, disminuye la demanda y la producción, y comienza la depresión. De acuerdo con Patel (2009: 72), Keynes pudo entender la sicología colectiva del mercado y advirtió que durante los tiempos de depresión la virtud de ahorrar de las personas puede convertirse en un vicio. Keynes observó también la resistencia de los trabajadores a aceptar reducciones a sus salarios nominales, pero además consideró que una baja generalizada de éstos no conlleva un aumento de la ocupación, como creía Pigou, sino a su disminución porque en el momento de bajar el ingreso de los asalariados disminuye el consumo y, por lo tanto, la demanda de trabajadores para producir bienes.

${ }^{3}$ Fue a raíz de esta crisis que se instauró el seguro de desempleo en Estados Unidos.

${ }^{4}$ El pensamiento neoclásico se basa en el comportamiento de las firmas y en la forma en que se establecen los precios, ganancias y salarios de acuerdo con las herramientas de análisis de la teoría de la utilidad marginal. 


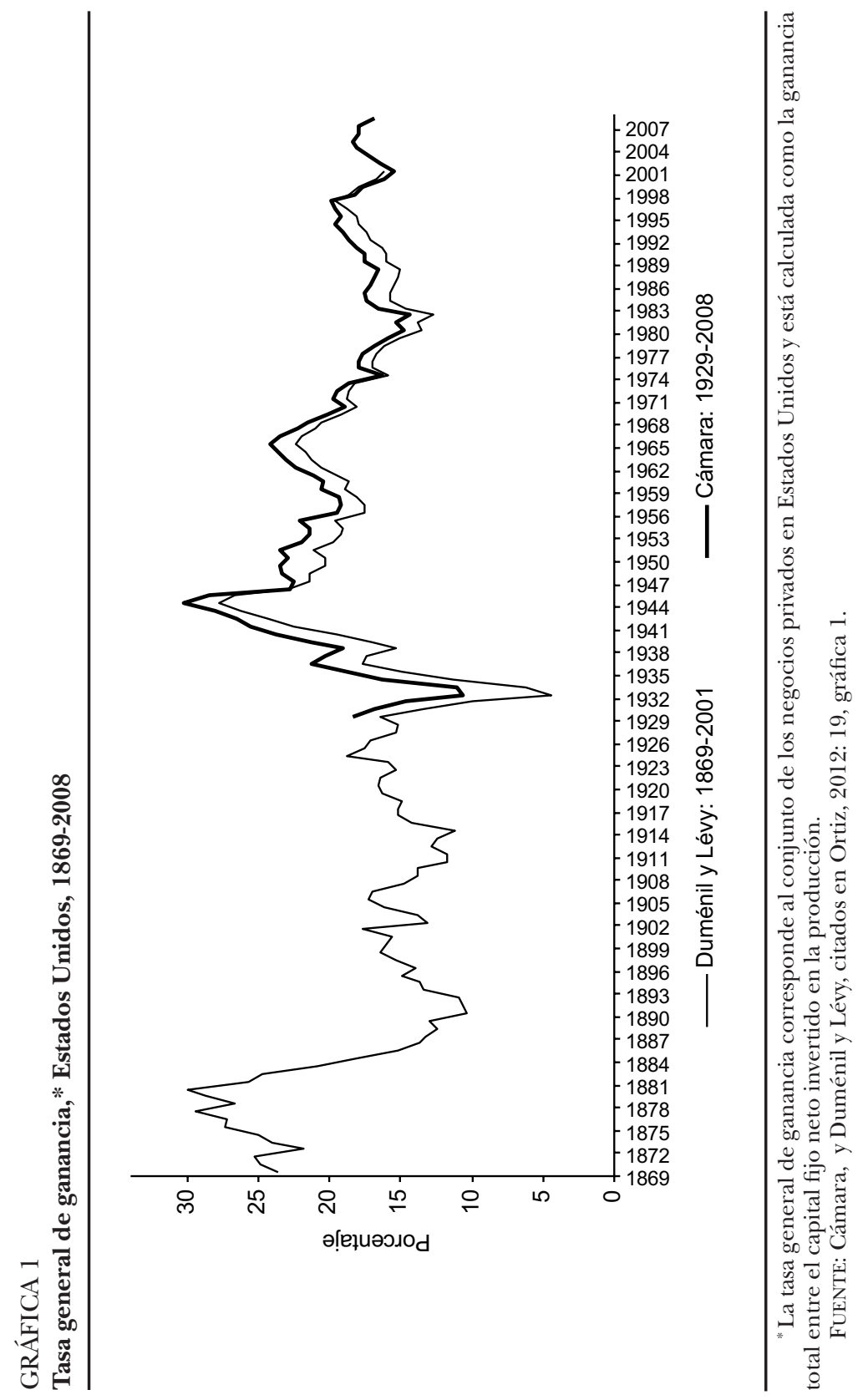


Keynes propuso una serie de medidas económicas para compensar los efectos negativos de las crisis. Básicamente sugirió que el gobierno sustituyera la acción de las empresas privadas durante los periodos de crisis hasta que la economía volviera a equilibrarse. El Estado tenía que estimular la demanda mediante el aumento del gasto público debido a que ello generaba efectos multiplicadores en la economía. Como plantea Patel (2009: 73), los mercados requieren del gasto público, sobre todo en las crisis, debido a la falta de confianza entre los inversionistas, corrigiendo así los errores del comportamiento colectivo. Con base en los planteamientos de Keynes, se promovió el pleno empleo y se desarrollaron estados de bienestar que procuraron una redistribución del ingreso mediante tasas impositivas progresivas y elevadas para quienes tenían ingresos altos, lo cual permitió financiar un sinfín de servicios sociales.

Si bien en los años dorados de la segunda posguerra el alza de los salarios en los países occidentales evitó que se presentara un excedente de producción, ésta tuvo efectos negativos en la tasa de ganancia, lo que desembocó en las crisis de los años setenta, agudizadas por el alza en los precios del petróleo. En la gráfica 1 observamos cómo a partir de entonces la economía de Estados Unidos comenzó a experimentar la baja de la tasa de ganancia durante un largo periodo. Como respuesta, ese país, al igual que Gran Bretaña y Chile, impuso políticas económicas de corte neoliberal, entre las que destacan la reducción de los beneficios asociados al trabajador (salarios, prestaciones, etc.), un recorte del gasto público y una baja en las tasas impositivas, sobre todo para la población de más altos ingresos. Las medidas no fueron efectivas y se agudizaron las dificultades para colocar el excedente petrolero. El aumento en los precios del petróleo generó inflación en los países ricos, lo que llevó al incremento en las tasas internacionales de interés que desembocó en la crisis de la deuda de los años ochenta, la cual sumió a los países pobres y de ingreso medio -altamente endeudados- en un periodo prolongado de estancamiento económico. A partir de ese momento en esos países se inició la aplicación de las reformas estructurales de corte neoliberal mediante una alianza entre gobiernos y élites a fin de reducir los costos de la fuerza de trabajo y de liberar los mercados de bienes y de capital.

Arturo Guillén (2008) identifica tres grandes cambios que los segmentos más poderosos del capital y los gobiernos impulsaron a partir de los años setenta para tratar de hacer frente a las crisis: 1) una gran ofensiva del capital contra el trabajo ("flexibilidad" laboral, des- 
mantelamiento de la seguridad social y de los sistemas de bienestar, intensificación del trabajo, etc.); 2) la apertura y la desregulación de los mercados de bienes y financieros, y 3) un régimen de acumulación con dominación financiera o "financiarización", en el cual las finanzas imponen su lógica de operación al conjunto del sistema. Para este autor la financiarización está en el corazón de las crisis de 2008.

Algunos autores sostienen que con esas reformas la economía global experimentó una expansión a inicios de los años noventa, sobre todo por el impulso a la mayor globalización, pero a finales de esa década un grupo de economías asiáticas entró en crisis, lo que provocó una nueva depresión mundial que duró poco tiempo ${ }^{5}$ gracias al dinamismo que generó la revolución de las telecomunicaciones en los mercados. Aun con la recuperación, en 2000 ocurrió otra crisis financiera que afectó a la mayoría de los países del mundo. Con ello Estados Unidos vivió un periodo de recesión en 2001 y 2002 (véase la caída de la ganancia en esos años en la gráfica 1), el cual fue superado por el boom inmobiliario ${ }^{6}$ que años más tarde desembocara en la crisis de 2008. De esta forma, explica Guillén, la burbuja financiera que sostuvo la economía mundial a finales del siglo pasado fue sustituida por la burbuja inmobiliaria, pero la saturación en este mercado provocó un aumentó estrepitoso en la cartera vencida y, dada la bursatilización hipotecaria, diversos agentes financieros (bancos, intermediarios no bancarios, aseguradoras, etc.) se vieron envueltos en una crisis sistémica.

La grave situación de la economía en Estados Unidos en el momento de la crisis se puede deducir mediante la gráfica 2, que muestra el coeficiente de deuda-ingreso de las empresas y el de los hogares, así como el de la hipoteca-ingreso de quienes tenían este tipo de deuda para el periodo 1960-2009. Es claro cómo a inicios de los años ochenta los coeficientes de endeudamiento empezaban a presentar una tendencia cre-

${ }^{5}$ De acuerdo con Paul Krugman (2009) esta crisis se inició a mediados de 1997 en Tailandia, donde el gobierno había aplicado cambios de política económica que supuestamente permitirían al país competir ventajosamente en los mercados financieros internacionales. La apertura permitió una entrada masiva de capital que fue invertido mayormente en el sector inmobiliario, lo cual creó una sobreoferta en dicho sector, que generó que la economía entrara en crisis. Los capitales financieros pudieron salir fácilmente gracias a la liberación de los mercados de dinero; se produjo un rápido contagio de la crisis hacia otros países asiáticos debido a que los grandes capitales invierten en "bloque": si un sólo país de la región falla, sacan el dinero de toda ella. Así, lo que parecía una pequeña crisis hundió a los países del este asiático en una de las peores crisis de la historia reciente.

${ }^{6}$ El valor de los inmuebles en Estados Unidos subió 93\% entre 1997 y 2006. 
ciente, después de que entre 1960 y 1982 se mantuvieron en niveles altos, pero estables. Como dijimos, la prolongada crisis de los ochenta sólo fue superada con una nueva burbuja financiera (la de telecomunicaciones) y a partir de 2000 los niveles de endeudamiento de todos los agentes económicos comenzaron a ser inmanejables. La gráfica 2 muestra que desde inicios de la primera década del presente siglo el endeudamiento de las familias había rebasado $100 \%$ de su ingreso, y el de las que tenían deuda hipotecaria también era muy elevado. El flujo de ingreso de hogares y empresas dejó de ser suficiente para cubrir los pagos del servicio de la deuda. El deterioro del poder adquisitivo de los hogares se produjo por la desvalorización creciente de la fuerza de trabajo, producto de la falta de crecimiento del salario real y del aumento de la flexibilización del trabajo. Como consecuencia de ello, las empresas empezaron a enfrentar una crisis de sobreproducción global de mercancías, lo que conllevó a una caída de la tasa de ganancia, e hizo cada vez más difícil la expansión económica. Como se deduce de lo anterior, la principal herramienta para intentar contrarrestar las constantes crisis en la era moderna ha consistido en la expansión de la demanda de bienes de consumo mediante el endeudamiento de las familias, lo cual las coloca en una situación de vulnerabilidad creciente e insolvencia ante los cambios en las condiciones económicas o de financiamiento.

$\mathrm{Si}$ a este panorama se suma la desaceleración en el crecimiento del producto interno bruto (PIB) de Estados Unidos, que bajó de 4.2\% en 2000 a $1.1 \%$ en $2001,{ }^{7}$ es claro que se generó un alto riesgo sistémico. Sobra decir que el panorama era mucho más desfavorable para las familias debido al enorme peso que adquirieron sus hipotecas como resultado de la burbuja inmobiliaria. Como veremos, a raíz de la crisis de 2008 el gobierno de Estados Unidos emprendió un programa de salvamento de bancos sin precedentes en la historia, aunque la vulnerabilidad de las empresas y las familias no se modificó de manera sustancial, ya que el programa no cambió los niveles de endeudamiento precrisis; pero además tampoco logró impulsar el crecimiento de la economía: en 2008 y 2009 se contrajo 0.4 y $3.1 \%$, respectivamente. Si bien a partir de 2010 el PIB ha tenido crecimientos positivos, éstos han sido tan bajos que resultan insuficientes para reactivar la economía global, que de acuerdo con el Banco Mundial sólo creció 1.8 y 2.2\% en 2011 y 2012, respectivamente.

${ }^{7}$ Información obtenida de <http://datos.bancomundial.org/indicador/NY.GDP. MKTP.KD.ZG> (consulta: enero de 2014). 


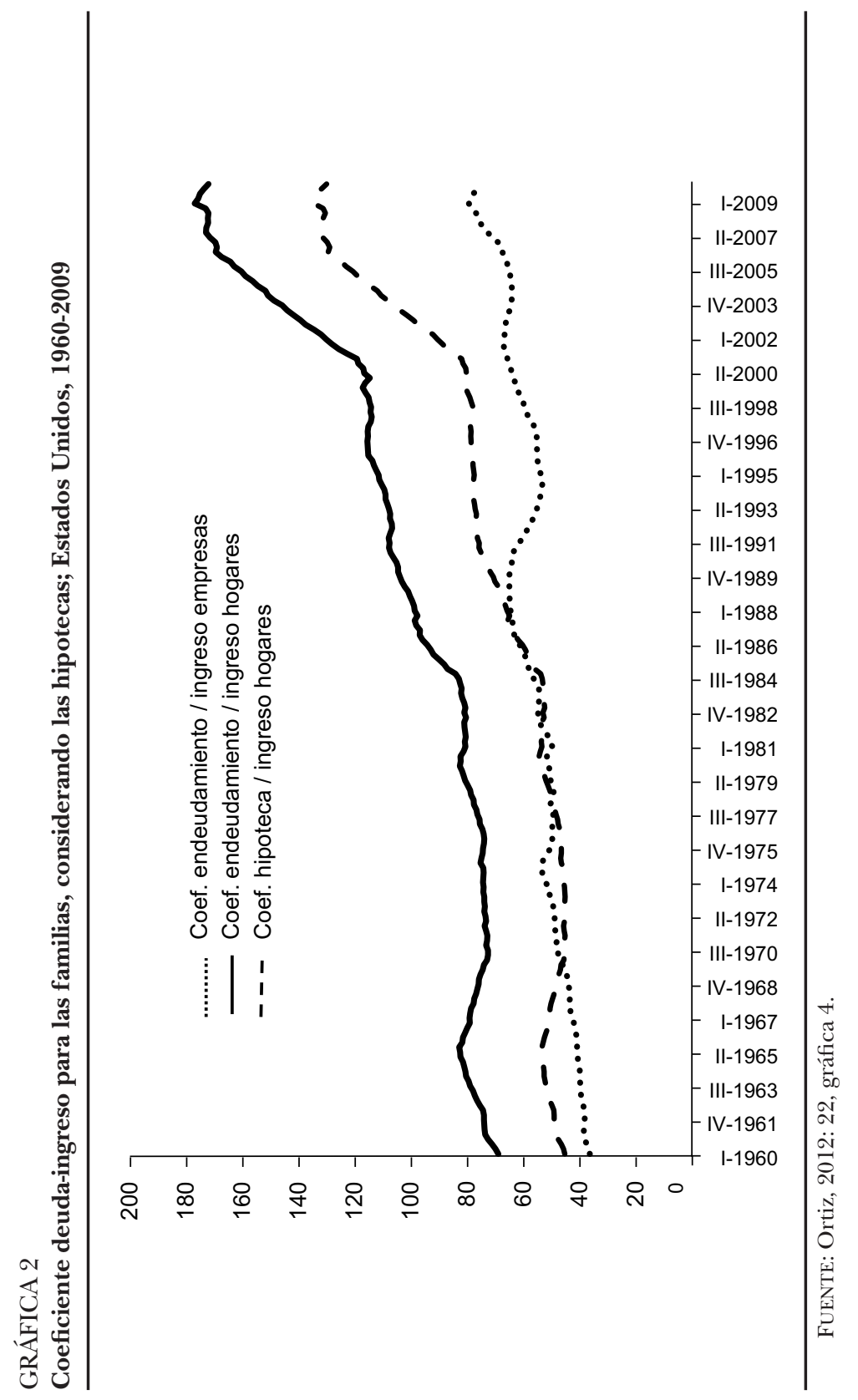


A raíz de la crisis de 2008 la economía de la Unión Europea se sumió también en un estancamiento prolongado. En 2009 tuvo una tasa de crecimiento negativa (de $-4.5 \%$ ) y aunque retornó a valores positivos en 2010 y 2011, éstos fueron muy bajos (de 2.1 y $1.6 \%$, respectivamente). Para contrarrestar las crisis los gobiernos europeos instrumentaron severas medidas de ajuste que afectaron seriamente las condiciones de vida de sectores amplios de la población. La ineficacia de tales medidas se refleja en el crecimiento económico, que se tornó negativo en $2012(-0.4 \%)$ y en 2013 aumentó a una tasa insignificante $(0.1 \%){ }^{8}$

La contracción económica ha mermado la capacidad financiera de la mayoría de los gobiernos, la cual era ya limitada debido a que, como dijimos, se redujeron las tasas impositivas para las clases altas y las empresas; en consecuencia los organismos internacionales y los países de mayor influencia en Europa, como Alemania y Gran Bretaña, promovieron una reducción del gasto social como parte de las medidas para compensar los efectos de las crisis. Con ello se inició un nuevo proceso de desmantelamiento de los estados de bienestar en los países que habían resistido la carrera hacia abajo en materia laboral y prestaciones sociales, siendo los más afectados de Europa Grecia, Portugal, Francia y España; no obstante, también se observan retrocesos en otros países como Alemania y Gran Bretaña.

La profundización global de la crisis se manifiesta en la persistencia del desempleo, el cual se mantiene en niveles altos a pesar de haberse superado los síntomas más graves de la crisis de 2008-2009. En Estados Unidos la desocupación llegó a 10\% en octubre de 2010 y en la actualidad se ubica por arriba de $6 \%$, nivel superior al que se tuvo en la precrisis (4.4\% en marzo de 2007). ${ }^{9}$ En Europa la tasa de desempleo ha seguido una tendencia al alza, ubicándose por arriba del $10 \%$ en promedio; pero afecta a más de un cuarto de la población econó-

${ }^{8}$ Cabe resaltar que la contracción económica en algunos países de la Unión Europea fue mucho más elevada que la del promedio. En algunos casos no ha mejorado desde 2009, particularmente en Grecia (con un decrecimiento que ha fluctuado de 3.1 a $7.1 \%$ ), Portugal (con caídas de 1.6 y $3.2 \%$ ); España (con reducciones de entre 0.4 y $3.1 \%$ ). Asimismo, aunque en 2010 los países con economías más grandes tuvieron tasas positivas, desde 2011 han sufrido fuertes desaceleraciones, sobre todo Francia, Reino Unido, Alemania e Italia (este último país con crecimiento negativo en 2012 y 2013). Véase $<$ http:/ / epp.eurostat.ec.europa.eu/tgm/table.do?tab=table\&init=1\&plugin=1\& language $=$ en $\&$ pcode $=$ tec $00115>$.

${ }_{9}$ Bureau of Labor Statistics (varios años), "Databases, Tables and Calculators by Subject", Washington, United States Department of Labor, <http://data.bls.gov/ timeseries/LNS14000000> (consulta: enero de 2014). 
micamente activa en España y Grecia (26.9\% en ambos), y en otros países se ubica en niveles más elevados que el promedio (Portugal, 17.6\%; Croacia, 16.5\%; Eslovaquia, 14.2\%, e Irlanda. 13.6\%). ${ }^{10}$ Debe considerarse además que el aumento del desempleo ha provocado problemas sicológicos en los desocupados. ${ }^{11}$ La reacción de los gobiernos para enfrentar esta situación ha sido recortar los beneficios asociados al desempleo, ${ }^{12}$ como ha sucedido en España.

Como resultado del deterioro salarial, el alto desempleo y la reducción de las prestaciones sociales en esos países, los nuevos pobres se ven obligados a buscar formas alternativas de sobrevivencia, como el tener acceso a alimentos baratos o gratuitos y evitar los desahucios. En Grecia, uno de los países más afectados por la crisis europea, los indicios del deterioro de las clases medias muestran que las familias han recurrido a formas más económicas para la satisfacción de sus necesidades. ${ }^{13}$ Asimismo, fuentes oficiales de Alemania informaron que mientras que antes de la crisis de 2008 pocas personas asistían a sus 700 comedores públicos, en 2011 la cifra ascendía a un millón al día. ${ }^{14}$ Pero quizá una de las manifestaciones más fuertes del deterioro de las condiciones de vida de la fuerza de trabajo consiste en el desalojo masivo de familias de sus viviendas, sobre todo en Estados Unidos y en España. No se tienen cifras oficiales mundiales sobre el número de hogares que perdieron sus viviendas a raíz de la crisis inmobiliaria de 2008, pero se estima que en 2013 tan sólo en Estados Unidos había llegado a cuatro millones. ${ }^{15}$

Cabe destacar que los desalojos son realizados por corporaciones bancarias rescatadas de la bancarrota por el gobierno norteamericano con dinero público. La situación llegó a niveles críticos, por lo que en

${ }^{10}$ Datos provenientes de Eurostat <epp.eurostat.ec.europa.eu/tgm/table.do; jsessionid> (consulta: julio de 2013).

${ }^{11}$ De acuerdo con Raventós (2012), en España "el 34\% de la gente que padece desempleo sufre problemas psicológicos, a diferencia de los que tienen trabajo, que es del 16\%".

12 En enero de 2013 el gobierno español anunció una reducción del 60 al $50 \%$ del salario en la prestación por desempleo, a partir del sexto mes de no tener empleo, para los nuevos perceptores.

${ }_{13}$ De acuerdo con reportes periodísticos, durante los inviernos las estufas de leña, antes consideradas símbolo de pobreza, estaban siendo vendidas con gran intensidad o eran compradas por pobres y ricos por igual (La Jornada, 28 de noviembre de 2011).

${ }^{14}$ Declaraciones del director del Parity Welfare de Alemania (La Jornada, 28 de noviembre de 2011).

${ }_{15}$ Muchas familias se quedaron sin casa o se mudaron con amigos o parientes, otras ingresaron en refugios de emergencia o vivían en las calles. Véase $<$ http:/ / pueblos sinfronteras.wordpress.com/2013/03/05/familias-resisten-en-estados-unidos-los-desalojosde-sus-viviendas-ordenados-por-los-bancos> (consulta: enero de 2014). 
2010 el Centro de Derechos a la Vivienda y Contra los Desalojos Abusivos (COHRE), con sede en Ginebra, realizó un llamado urgente al gobierno de ese país para que reconociera que tener vivienda es un derecho humano. De forma similar, la relatora especial sobre vivienda de la ONU manifestó su preocupación debido a que en ese mismo año “aproximadamente 12.7 millones de niños estadounidenses -uno de cada seis- vivían en hogares en los que más de la mitad del ingreso se gasta en vivienda" ${ }^{16} \mathrm{El}$ desahucio, por otra parte, ha llevado a algunas personas afectadas al suicidio, sobre todo en España, Grecia, Chipre e Italia, países que tuvieron tasas bajas de suicidio antes de la crisis, pero que se dispararon a partir de ésta. ${ }^{17}$

También ciertas economías que mantuvieron un crecimiento positivo aun en la crisis (por ejemplo, Brasil, China, India, Bolivia, Venezuela, Argentina, Uruguay y Corea del Sur), han sido afectadas por ésta. Algunos países del grupo denominado los BRICS (Brasil, Rusia, India, China y Sudáfrica) presentaron signos de desaceleración. De esta forma, mientras que Brasil, India y China mantuvieron tasas de crecimiento altas en la primera década del presente siglo (de 4.1, 7.8 y $11.3 \%$ respectivamente entre 2000 y 2010), en 2012 la economía de Brasil sólo creció $0.87 \%$, la de India tuvo una contracción de $3.24 \%$ y la de China creció a una tasa sustancialmente menor a la observada en la década anterior $(7.8 \%) .{ }^{18}$ En estos países que mostraron mejor desempeño, desde antes de la crisis de 2008, sus gobiernos aplicaron políticas económicas y sociales contrarias a las recomendadas por los organismos financieros: otorgaron beneficios más altos y con mayor cobertura así como aumentos salariales superiores a los observados en las dos últimas décadas del siglo pasado. Ello no ha evitado el deterioro en las condiciones de vida de algunos sectores de su población, además de que los alcances de dichas políticas fueron limitados y no lograron frenar las manifestaciones de descontento social en las que la población exigía mayores beneficios; tales son los casos de Brasil (en 2013), Chile (con el movimiento estudiantil) y Bolivia (con la exigencia de mejoras salariales en el sector minero).

16 <http://www.cohre.org/news/press-releases/usa-asombrosas-violaciones-alderecho-a-la-vivienda-dice-enviado-a-la-onu> (consulta: enero de 2014).

$17<\mathrm{http} / /$ :elmundo.es/elmundo/2013/02/27/espana/1361964219.html >. De igual forma, Raventós (2012) cita cifras de suicidio en España anteriores a la crisis y las compara con las ocurridas una vez que inició el desahucio. En 2005 se registraron 2227 suicidios, en 2008 aumentaron a 3453 y en 2009 a 3429 .

${ }_{18}$ Datos provenientes de: <http://datos.bancomundial.org/indicador/NY.GDP. MKTP.KD.ZG/ countries? display=default $>$ (conculta: enero de 2014). 
Como hemos visto, el sistema económico global ha presentado episodios recurrentes de crisis que han conducido al deterioro de las condiciones de vida de la mayoría de la población. Estas crisis han afectado no sólo a los habitantes de los países pobres, también a la clase trabajadora de los ricos, que presenta carencias importantes en la satisfacción de sus necesidades. Como veremos en la siguiente sección, la crisis económica se ha conjugado con una crisis social y una ambiental, pero mientras que se agudiza la precariedad en las formas de vida de las clases bajas a escala global, las recomendaciones de política económica han conducido a una rápida recuperación de los ingresos de las clases altas y de las grandes empresas, aumentando así la desigualdad.

\section{Crisis social}

\section{Desigualdad social y pobreza}

La desigualdad es la manifestación de los desbalances de poder dentro de la sociedad, y ha aumentado en forma acelerada en los últimos años. De acuerdo con Pogge (2009), en 1820 la relación del ingreso del 20\% más rico respecto al 20\% más pobre del mundo era de 3 a 1; en 1913 llegó a 11 a 1, y a finales del siglo pasado (1997) era de 74 a 1. Existe suficiente evidencia para afirmar que a raíz de la crisis de 2008 la desigualdad creció de manera acelerada. Por ejemplo, en 2010 se reportó que los 11 millonarios más prósperos del mundo (alrededor de $0.15 \%$ de la población mundial) habían recuperado las pérdidas provocadas por dicha crisis y su fortuna sobrepasaba a la que poseían en 2007. ${ }^{19}$

Además la naturaleza de la desigualdad se ha transformado. Krugman (2013) argumenta que por décadas la desigualdad era resultado de las diferencias entre los ingresos de los trabajadores de alto y los de bajo nivel, tanto en Estados Unidos como en otros países ricos del orbe, pero que a partir de 2000 la desigualdad se manifiesta en una disminución de la proporción que representan los salarios en el producto total frente a la proporción de las ganancias, lo que implica que son los dueños de los medios del capital quienes se han apropiado de

${ }^{19}$ La fortuna de los millonarios más ricos del mundo ascendía en 2010 a 42.7 billones de dólares ("trillones" en el uso anglosajón), en comparación con los 40.7 billones de dólares que tenían en 2007 (Capgemini y Merrill Lynch, 2011: 4). 
manera creciente de los frutos del trabajo en los últimos años. En México también se observa este fenómeno: mientras que en 1976 las remuneraciones por trabajo representaban $43.5 \%$ del ingreso nacional, su porcentaje bajó a $30.3 \%$ en $2011,{ }^{20}$ lo que muestra que el desbalance en las relaciones de poder entre los trabajadores y los capitalistas se ha agudizado recientemente.

Desde otra perspectiva, podemos decir que a escala global el grado de concentración del ingreso es muy elevado si consideramos que a finales del siglo pasado las personas que vivían en los hogares más pobres del mundo (los pobres de los países pobres) y que representaban $43 \%$ de la población total, sólo concentraban el 1.1\% del ingreso mundial, mientras que las que habitaban en los países más ricos y que constituían tan sólo $16 \%$ de la población, concentraban $80.5 \%$ del ingreso global (véase la gráfica 3). De igual forma tenemos que el consumo per cápita era 80 veces mayor en Occidente que el que se tenía en África Subsahariana, y se estimaba que aproximadamente un cuarto de la población del mundo consumía tres cuartas partes de la energía primaria global (Doyal y Gough, 1991).

El aumento de la desigualdad se manifestó también en el ritmo de crecimiento del consumo de los hogares por estrato social. Así, mientras que el gasto acumulado en consumo de la población de mayores ingresos del planeta ( $50 \%$ más rica) creció $52.7 \%$ en términos reales entre 1990 y 2001, el de la población con el 10\% de ingreso más bajo sólo tuvo un crecimiento real de $12.9 \%$ (véase la gráfica 4). Además, el del percentil más pobre del mundo tuvo una baja real de $7.3 \%$, y aunque el crecimiento del consumo se vuelve positivo a partir del segundo percentil, sólo aumentó $1 \%$ y en el tercero 6.6 por ciento.

Además de la enorme desigualdad, existe un elevado nivel de pobreza en el mundo; su existencia representa siglos de explotación en los que un pequeño grupo de la sociedad se ha apropiado de la tierra, los recursos naturales y el trabajo de la mayoría de la población. Podemos decir entonces que la riqueza de pocos descansa sobre la pobreza de la mayor parte de los habitantes del planeta.

Este flagelo es tan elevado que, aun cuando se toman los míseros parámetros del Banco Mundial (BM), el número de pobres ultraextremos en el mundo se estimó en cerca de mil millones de personas en 2005; esta cantidad fue calculada con base en una línea de pobreza

20 Unite, con datos del Sistema de Cuentas Nacionales de INEGI, La Jornada, 22 de julio de $2013<$ http://www.jornada.unam.mx/2013/07/22/economia/023oleco $>$. 


\section{GRÁFICA 3}

Porcentaje del ingreso global que concentran los hogares más pobres del mundo (que viven con menos de un dólar), los de los países más ricos y el resto de los países

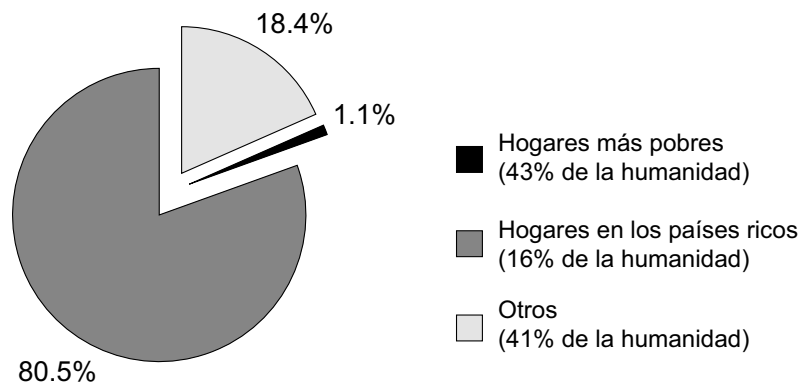

FUENTE: Elaboración propia con base en Pogge, 2009.

extrema de 1.25 dólares al día por persona (Chen y Ravallion, 2008).21 El propio BM reconoce que este umbral es muy bajo para países como los de América Latina, por lo cual utiliza otros umbrales más elevados, correspondiendo a esta región el de 2.50, con el que la mitad de la humanidad (3 140 millones) quedaba clasificada en pobreza extrema en 2005 (véase Chen y Ravallion, 2008; Ravallion, 2008).

Los datos anteriores no incluyen a los pobres del primer mundo, que en su mayoría tienen ingresos superiores a 2.50 dólares por día, pero aun así sufren pobreza y hambre. En Estados Unidos la línea oficial de pobreza en 2012 fue de 16.2 dólares por persona al día, y se consideraron como pobres a $15.9 \%$ de la población (véase la gráfica 5 ). Este porcentaje representa 48.8 millones de personas. ${ }^{22}$

${ }^{21}$ Pogge y Reddy (2009) han criticado la línea de pobreza (LP) del BM, ya que su definición está basada en el valor de las LP extremas de los países más pobres del mundo, generalmente localizados en África. Para su conversión se utilizan los dólares de paridad de poder adquisitivo (PPA), que supuestamente nos dicen cuántas unidades de moneda local se requieren para adquirir un conjunto de bienes similar a lo que podríamos adquirir con un dólar en Estados Unidos. Sin embargo, como explican, existen serias dificultades para convertir una moneda a otra, debido a que los términos de intercambio, en los cuales se basa dicha conversión, se establecen de acuerdo con la estructura de consumo en cada país, la cual no refleja la del gasto de los más pobres; pero además ésta se modifica con el tiempo y es muy sensible a las variaciones en los tipos de cambio.

${ }^{22}$ Esta cantidad resulta de tomar como parámetro el valor de la LP para una fami- 


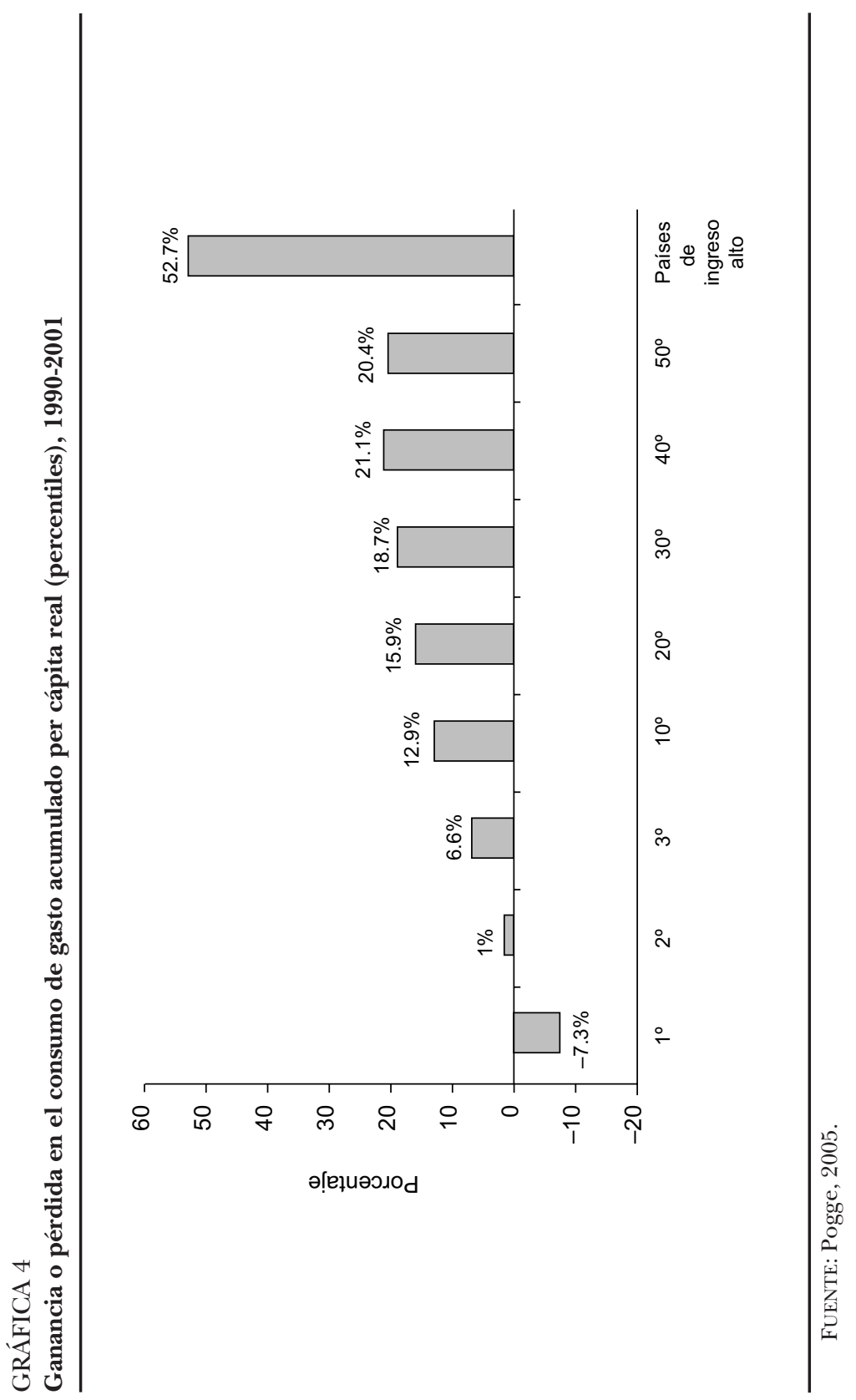




\section{GRÁFICA 5}

\section{Pobreza en Estados Unidos (años seleccionados, porcentaje de población)}

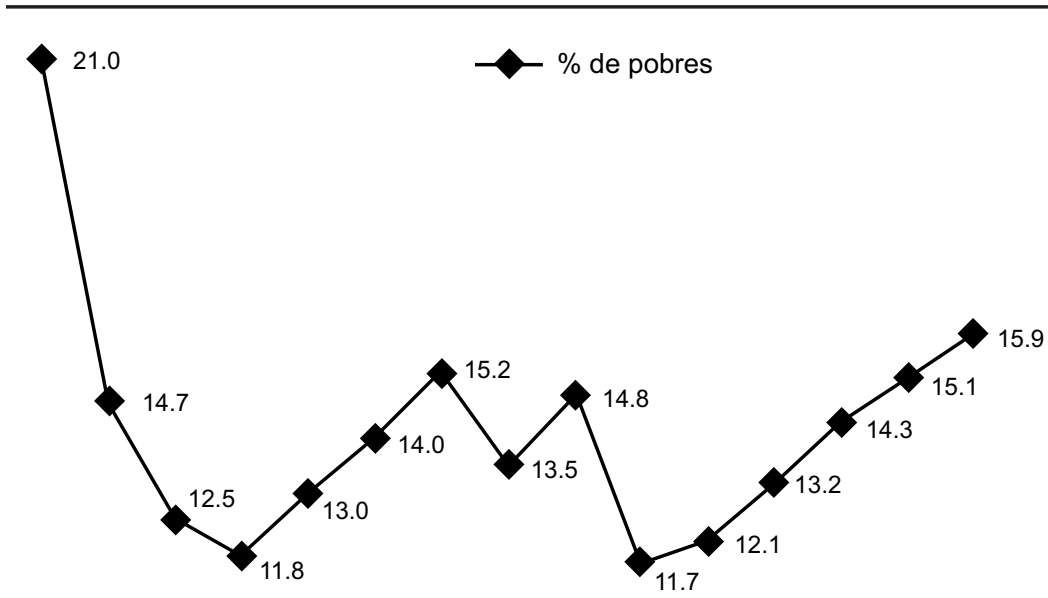

196219661971197619801981198319901992200120022008200920102012

FUENTE: Elaboración propia con base en datos provenientes del Bureau of Labor Statistics, varios años.

En la gráfica 5 se puede observar que la pobreza tuvo una fuerte disminución en los años sesenta y en 1976 alcanzó uno de sus niveles más bajos (11.8\%). En ese año inició la crisis por el alza de los precios del petróleo, que desembocó en la crisis de la deuda. Como resultado la pobreza en Estados Unidos se elevó en 1983 a 15.2\% de la población. Fue hasta inicios del presente siglo que la pobreza bajó a niveles similares a los de los años setenta (11.7\% en 2001), pero con la crisis inmobiliaria de 2008 y la subsecuente caída del ingreso de las familias, volvió a aumentar, a $15.9 \%$ en 2012 , lo que significa un retroceso de casi medio siglo.

La evolución de la pobreza en México mostró un patrón similar al de Estados Unidos. Tuvo una baja muy significativa durante los años

\footnotetext{
lia con dos adultos y dos menores. A partir de 2012 el gobierno norteamericano utiliza una segunda línea de pobreza para otorgar beneficios, que puede llegar a más de 20.8 dólares por persona al día, dado que incluye el costo de la renta de la vivienda. El porcentaje de pobreza no varía sustancialmente (16\% en 2012) y el número de pobres aumenta a 49.7 millones. La nueva metodología puede consultarse en <http://www. census.gov/how/infographics/poverty_measure-how.html>.
} 
sesenta y setenta; posteriormente subió, a partir de 1982, como resultado de la crisis de la deuda. Cabe mencionar que, a diferencia de lo sucedido en aquel país, la evolución favorable de la pobreza se prolongó en los setenta gracias al boom petrolero provocado por el alza de los precios de este producto.

Las tendencias descritas para México se muestran en la gráfica 6 . Ésta contiene cuatro series sobre la evolución de la pobreza en el país durante el periodo 1968-2000. La primera serie se refiere a los datos de la CEPAL (Comisión Económica para América Latina y el Caribe), la segunda a los del Banco Mundial (BM), la tercera fue construida con base en la Canasta Normativa de Satisfactores Esenciales (CNSE) ${ }^{23}$ y la cuarta con el Método de Medición Integrada de la Pobreza (MMIP). Los diferentes niveles de pobreza dependen de los umbrales y la metodología utilizada. ${ }^{24}$ Dos series (CEPAL y CNSE) cubren el periodo completo, mientras que la de BM finaliza en 1996 y la del MMIP inicia en 1984.

La rápida disminución de la pobreza entre 1968 y 1981 (en la serie de CEPAL de 42.5 a $36.5 \%$; en la del BM de 49 a $25 \%$ y en la de la CNSE de 72.6 a $48.5 \%$ ) obedeció a diversos factores, como la creación de empleos bien remunerados, la ampliación de los derechos sociales (el acceso a los servicios de salud, la seguridad social y la educación), la construcción de infraestructura para la población (electricidad, agua y drenaje, etc.), y los apoyos a la vivienda, entre otras acciones en las que el Estado jugó un papel decisivo. Pero, como mencionamos, la etapa de crecimiento económico promovido por la bonanza de la se-

${ }^{23}$ La CNSE fue elaborada para el estudio realizado por Coplamar (Coordinación Nacional del Plan General de Zonas Deprimidas y Grupos Marginados, 1983), bajo la dirección de Julio Boltvinik. Esta canasta incluye una lista de bienes y servicios (y sus cantidades anuales) necesarios para la satisfacción de las necesidades humanas. La CNSE ha sido utilizada por Boltvinik, Hernández Laos, Damián, Marín, entre otros investigadores (para conocer una explicación sobre cómo se elaboró la canasta véase Boltvinik y Marín, 2003).

${ }^{24}$ Las tres primeras series son cálculos de pobreza por ingresos; las líneas de pobreza utilizadas por el BM tienden a ser, como mencionamos, minimalistas (dos dólares al día para México), mientras que la de la CEPAL es similar a la que utiliza el gobierno mexicano, pero los ingresos de los hogares son ajustados a cuentas nacionales (CN) de acuerdo con la metodología del organismo, que reconoce que los hogares tienden a subreportarlo. Los cálculos de la CNSE tienden a ser más elevados debido a que no se realiza el ajuste y a que la canasta es más generosa que la de los organismos internacionales pues cubre un espectro más amplio de necesidades. Para el cálculo del MMIP se utilizan tres indicadores: de ingreso, de necesidades básicas insatisfechas (que cubre aspectos como acceso a los servicios de salud y la seguridad social, educación, vivienda, bienes durables, servicios de la vivienda, etc.) y de carencia de tiempo libre. El MMIP es el indicador más completo de las cuatro series, además de que su LP se basa en la CNSE (para conocer la metodología del MMIP véase Boltvinik, 1999 y 2005). 
gunda posguerra finalizó con la crisis de la deuda en 1982 y la pobreza en México se incrementó de manera notable a partir de entonces.

La instrumentación de las políticas neoliberales ${ }^{25}$ llevó al país a una espiral inflacionaria -debido a las sucesivas devaluaciones-e hizo a la economía altamente vulnerable a los shocks externos (véase Damián, 2002), por lo que con la caída de las bolsas internacionales en 1987 se experimentó una nueva crisis, lo que posteriormente volvió a suceder en 1994-1995 por la sobrevaluación del peso, que provocó una contracción económica y un aumento acelerado de la pobreza (véase la gráfica 6). Aunque después de 1996 se observa una baja de ésta, las pérdidas en materia social no lograron subsanarse, por lo que a finales del siglo Xx la pobreza está en niveles más altos que los de los años setenta. Conforme a los datos de la CEPAL, en el año 2000 se ubicaba en $41.1 \%$ de la población, mientras que en 1977 en 39.5\%; según los de la serie de la CNSE, las diferencias son de $68.5 \%$ frente a $58.0 \%$, respectivamente (véase la gráfica 6 ).

La falta de dinamismo económico, la elevada volatilidad financiera y una casi permanente recesión provocada por la búsqueda a ultranza de los equilibrios fiscales y las políticas procíclicas aplicadas en México han provocado que la pobreza tenga una tendencia al alza. Aun cuando entre 2000 y 2006 parecía que ésta comenzaba a reducirse, la crisis alimentaria provocada por el alza de los precios de los alimentos de 2006 y la crisis inmobiliaria de 2008 modificaron tal tendencia.

La gráfica 7 presenta cinco series con la evolución de la pobreza para el periodo 2000-2012. Éstas se construyeron con metodologías distintas de la gráfica anterior: dos corresponden al MMIP y fueron calculadas con una innovación metodológica en la que se consideran las economías de escala. ${ }^{26}$ La primera se refiere a la evolución de la pobre-

25 Entre las que destacan la privatización, la apertura comercial y la reducción de la participación del Estado en la economía y en la provisión de servicios sociales, así como en la disminución de subsidios a los productos básicos, entre otras.

${ }^{26}$ La estimación de la línea de pobreza y la normalización del ingreso con la metodología del MMIP anterior incorporaba las diferencias en los requerimientos nutricionales de los hogares, según su tamaño y las características de sus miembros (edad y sexo), y se expresaba en unidades adulto-equivalente. La nueva metodología incluye, además de la consideración de dichas diferencias, otras que se derivan de las economías de escala en el consumo y la producción doméstica. Se toma en cuenta que algunos bienes familiares son fijos (como el refrigerador o la estufa) y no necesitan aumentar cuando se incrementa el tamaño de la familia (dentro de ciertos rangos); pero también existen bienes familiares variables que se incrementan, pero menos que proporcionalmente, con el tamaño del hogar (la cantidad de gas, el número de cuartos, etc.). Las economías de escala derivan de ambos tipos de bienes familiares. 


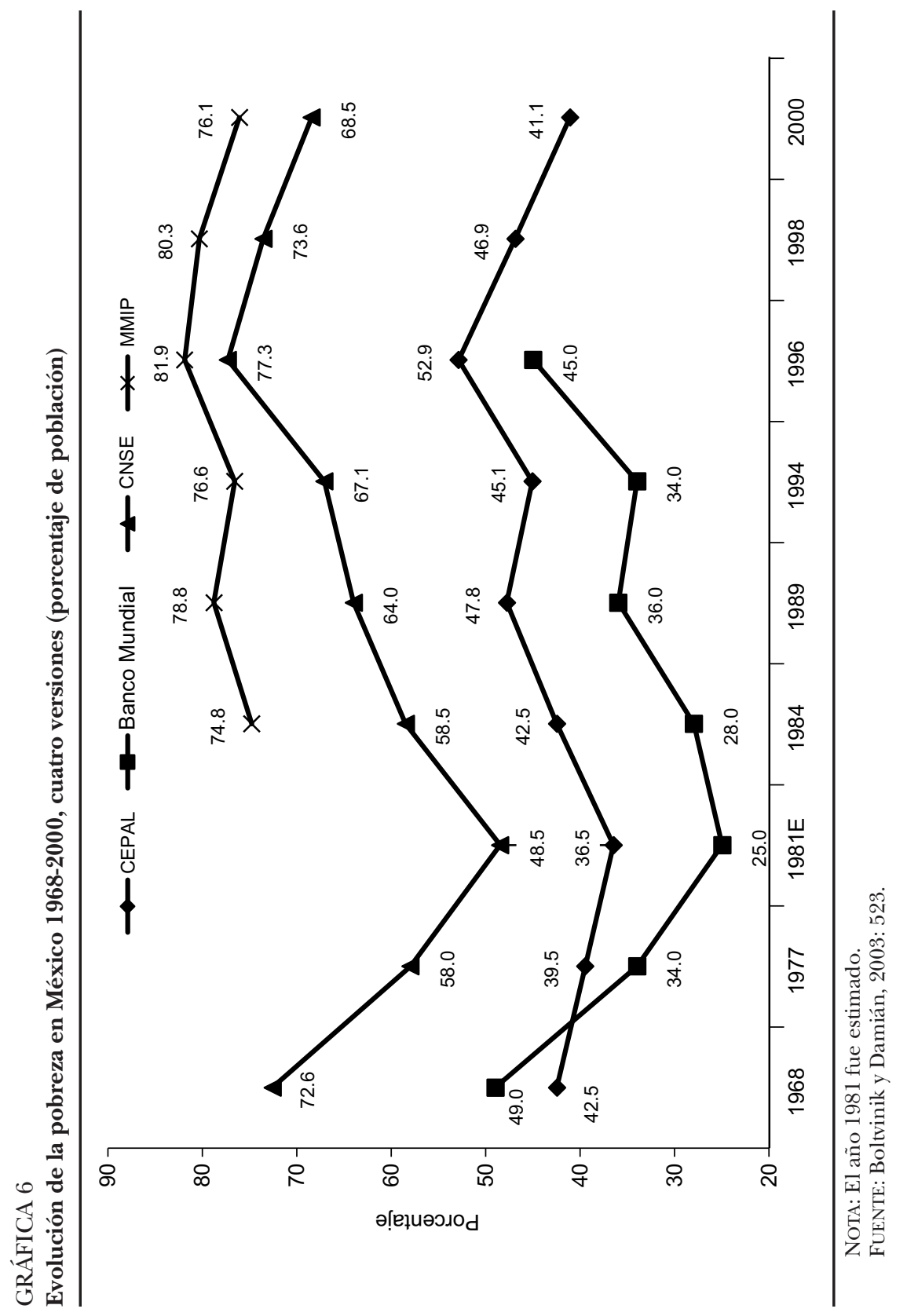


za extrema de acuerdo con este método (denotada con MMIPee) y la segunda al total. Como podrá constatarse, el nivel de pobreza extrema del MMIPee es similar al de la tercera serie, denominada por el gobierno federal como pobreza de patrimonio, y que se adoptó como la medida oficial entre 2000 y 2012. Por otra parte, el nivel de la pobreza total del MMIPee es similar al que resulta de sumar el porcentaje de pobreza multidimensional y del de la población que el Coneval (Consejo Nacional de Evaluación de la Política Social) denominó como vulnerable. ${ }^{27}$ Se observa que tanto la serie de pobreza extrema del MMIPee como la de patrimonio tienen una ligera tendencia a la baja hasta 2006, pero después aumentan debido a las crisis de los precios de los alimentos y la inmobiliaria. De esta forma, aunque la pobreza extrema del MMIPee se ubicaba en $50 \%$ de la población total en 2005, para 2012 representaba 54\%. La pobreza de patrimonio terminó el periodo en $52.3 \%$, cuando en 2006 representó 42.6\% (véase la gráfica 7).

En lo que respecta al total de pobreza según el MMIPee, podemos observar que tiene una tendencia similar ya que en 2006 presenta su nivel más bajo (79\%), pero con las crisis vuelve a aumentar a $83.1 \%$ en 2012, sólo tres décimas porcentuales por debajo del nivel de 2000. En la gráfica 7 se constata además que las carencias de la población mexicana están altamente generalizadas, ya que la serie de Coneval (que inicia en 2008 y que representa la suma de la población pobre multidimensional y la que tiene alguna carencia en la dimensión de ingreso o de privación social -población pobre más población vulnerable-), se ubica en niveles similares a los del MMIPee. En ambos casos, la población carente está por encima del $80 \%$ de la población total en 2012, es decir, que menos del $20 \%$ de la población en México tiene cubiertas sus necesidades humanas básicas (véase la gráfica 7). ${ }^{28}$

27 En 2008 el Coneval dio a conocer una nueva metodología oficial, pero ahora multidimensional, en la que definió como pobre a la población que presenta un ingreso bajo y además al menos una carencia en los indicadores de privación (salud, seguridad social, educación, seguridad alimentaria, vivienda e infraestructura básica de la vivienda). Denominó como población vulnerable a la que tiene un ingreso menor a la línea de pobreza, pero que no presenta carencia en los indicadores de privación; o viceversa, a la que tiene un ingreso superior a la línea de pobreza, pero tiene alguna carencia en dichos indicadores (para una crítica de esta metodología véase Damián, 2010a, b, c y d).

28 Es curioso constatar que en materia de satisfacción de necesidades humanas, en la actualidad la sociedad mexicana presenta una distribución similar a lo que se ha denominado el principio de Pareto; este autor encontró que 20\% de la población italiana del siglo XIX ostentaba el $80 \%$ del poder político y económico, el otro $80 \%$ de la población sólo poseía $20 \%$ de la riqueza restante y tenía poca influencia política. Como hemos visto, en la actualidad la concentración de la riqueza es aún mayor que en ese tiempo. 


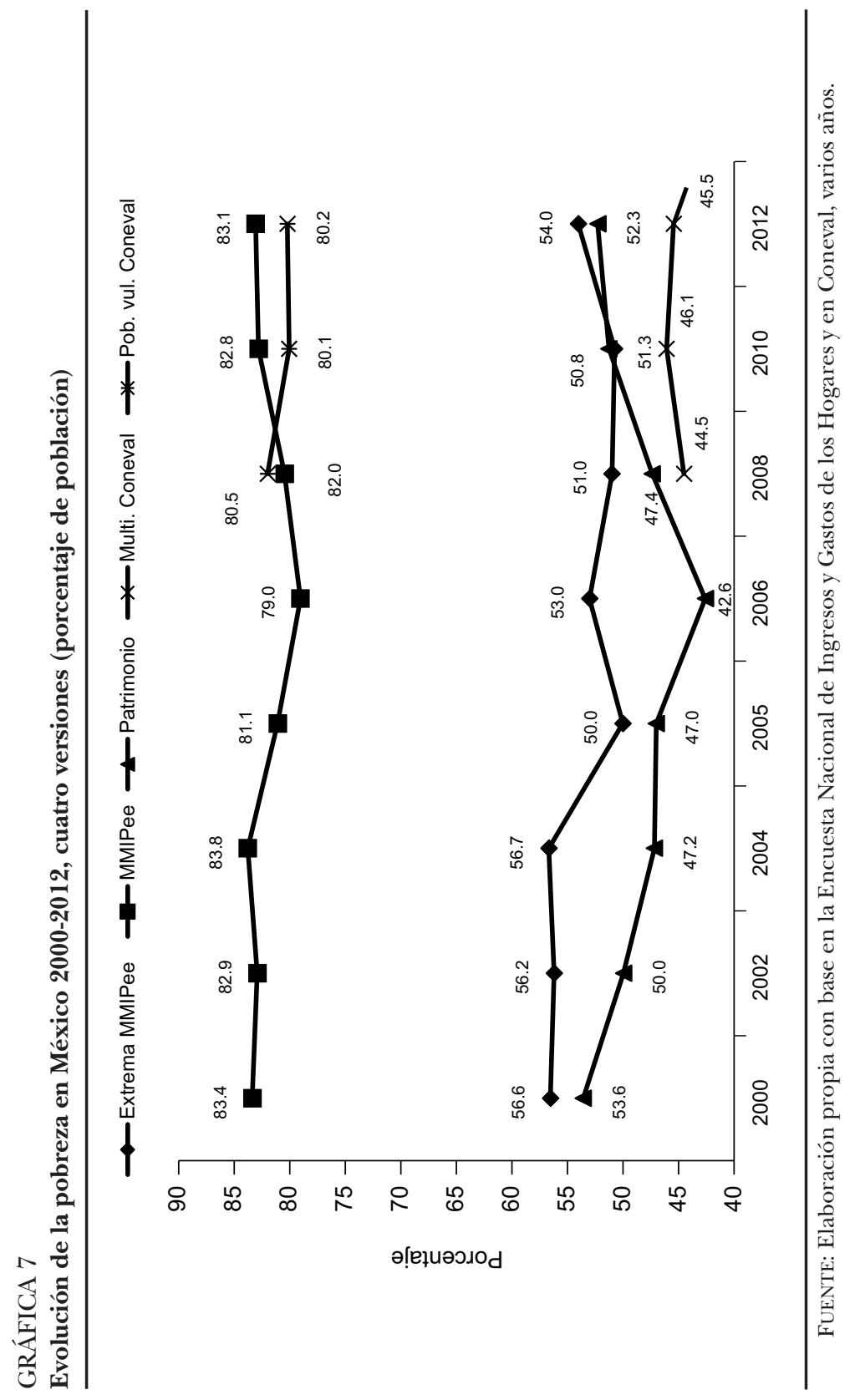


Tanto en México como en el mundo entero, el aumento de la pobreza ha venido acompañado, paradójicamente, por una mayor capacidad humana para erradicarla. Subsanar las carencias de los más pobres suele ser presentado como un gran reto para nuestra sociedad (como alcanzar las Metas del Milenio), pero como muestra Pogge (2009), sólo bastaría con destinar el 1\% del ingreso disponible del 10\% de la población más rica del planeta para abatir la pobreza extrema. Esta cifra equivale a invertir 40 mil millones de dólares por diez años (1995-2005), según el PNUD (2007: 126). La magnitud de los recursos es menor al gasto total en alimento para mascotas realizado en Estados Unidos y Europa (Gordon, 2004: 70). Con ello se lograría la cobertura total de los servicios sociales básicos de la población de los países en vías de desarrollo.

Para el caso de México podemos hacer un cálculo similar, tomando como parámetro la cantidad de recursos que se gastan en el subsidio que el gobierno otorga a las familias beneficiadas por el programa Prospera (antes Oportunidades) a partir de 2007 (120 pesos mensuales por hogar) con el fin de paliar el efecto en el ingreso del incremento en el precio de los alimentos. La fortuna de Carlos Slim, el hombre más rico del mundo, alcanzaría para financiar, sin intereses, las transferencias que reciben de Prospera 6 millones de hogares durante 128 años. No hay que olvidar que la fortuna de este magnate creció exponencialmente al ser beneficiario de la ola de privatizaciones ocurridas a partir de 1988, por la cual pudo obtener el servicio de telefonía nacional, que siendo ya una empresa privada se mantuvo cerrado a la competencia interna e internacional por casi diez años, con tarifas muy altas. Pero como mencionábamos, mientras que la riqueza permanecen concentrándose en pocas manos, las muertes por hambre continúan en niveles muy elevados, tema que abordaremos en la siguiente sección.

\section{Muertes por hambre}

Otra de las grandes paradojas de nuestra sociedad es la existencia de una elevada cantidad de muertes asociadas con la pobreza, que no pueden ser justificadas dado que el avance tecnológico en materia alimentaria y de salud permitiría tener las reservas de alimentos y los servicios sanitarios básicos para evitarlas. Amartya Sen (2000: prólogo) enfatiza no sólo el problema del hambre, sino el daño que se produce cuando es endémica, ya que: 
trabaja silenciosamente, en forma permanente, incrementando las tasas de mortalidad y afectando a una mayor proporción de la población que las hambrunas. La desnutrición persistente también emponzoña la existencia de la gente que probablemente no muera como resultado de ello, pero cuya habilidad para llevar una vida segura, productiva y feliz se ve severamente afectada por el debilitamiento y la morbilidad.

El hambre constituye un estado severo que ocasiona sufrimiento y enfermedad física, moral y mental; deteriora la condición humana, pues afecta no sólo al organismo, sino a una de las capacidades más nobles del ser humano: el raciocinio. Se estima que entre 1990 y 2005 ocurrieron 300 millones de muertes asociadas a la pobreza, cifra mucho mayor a cualquiera de las ocurridas durante los grandes episodios bélicos del siglo xx, en los que se cometieron atrocidades y genocidios (véase la gráfica 8).

Por otra parte, ha aumentado la pobreza alimentaria de un número importante de hogares y personas en algunos países pobres y de ingreso medio, sobre todo a partir de la crisis de la deuda de los años ochenta debido a que la mayoría de los gobiernos dejó de invertir en agricultura y se eliminaron los subsidios a la producción y al consumo básicos, como condición para obtener nuevos préstamos internacionales. La mayor dependencia de las importaciones de básicos ha hecho más vulnerables a los países importadores de alimentos por los vaivenes de la especulación. Esta situación es particularmente notoria en México, ya que en el primer trimestre de 2010 erogó 4291 millones de dólares para comprar alimentos en el mercado internacional (fundamentalmente en Estados Unidos), lo que representó un crecimiento de $14 \%$ respecto de igual periodo en 2009 . Entre los principales productos importados se encuentran: maíz, frijol, trigo y leche y sus derivados (Zúñiga, 2011 y 2012). Asimismo, según informes oficiales, la dependencia alimentaria nacional ${ }^{29}$ se ha deteriorado enormemente, ya que entre 1995 y 2011 las importaciones de maíz aumentaron de 12.7 a $25 \%$ del consumo nacional, las de trigo de 28.3 a $50.9 \%$, las de arroz de 50.8 a $75.4 \%$ y las de frijol de 2 a $9.7 \%$ (Presidencia de la República, “Anexo estadístico”, Quinto informe de gobierno, 2011).

Pero mientras la carencia alimentaria crece en algunos países y la población más pobre del planeta carece de ingresos o de recursos suficientes para adquirir los alimentos requeridos para no padecer

29 Se calcula mediante la relación importaciones/consumo aparente nacional. 


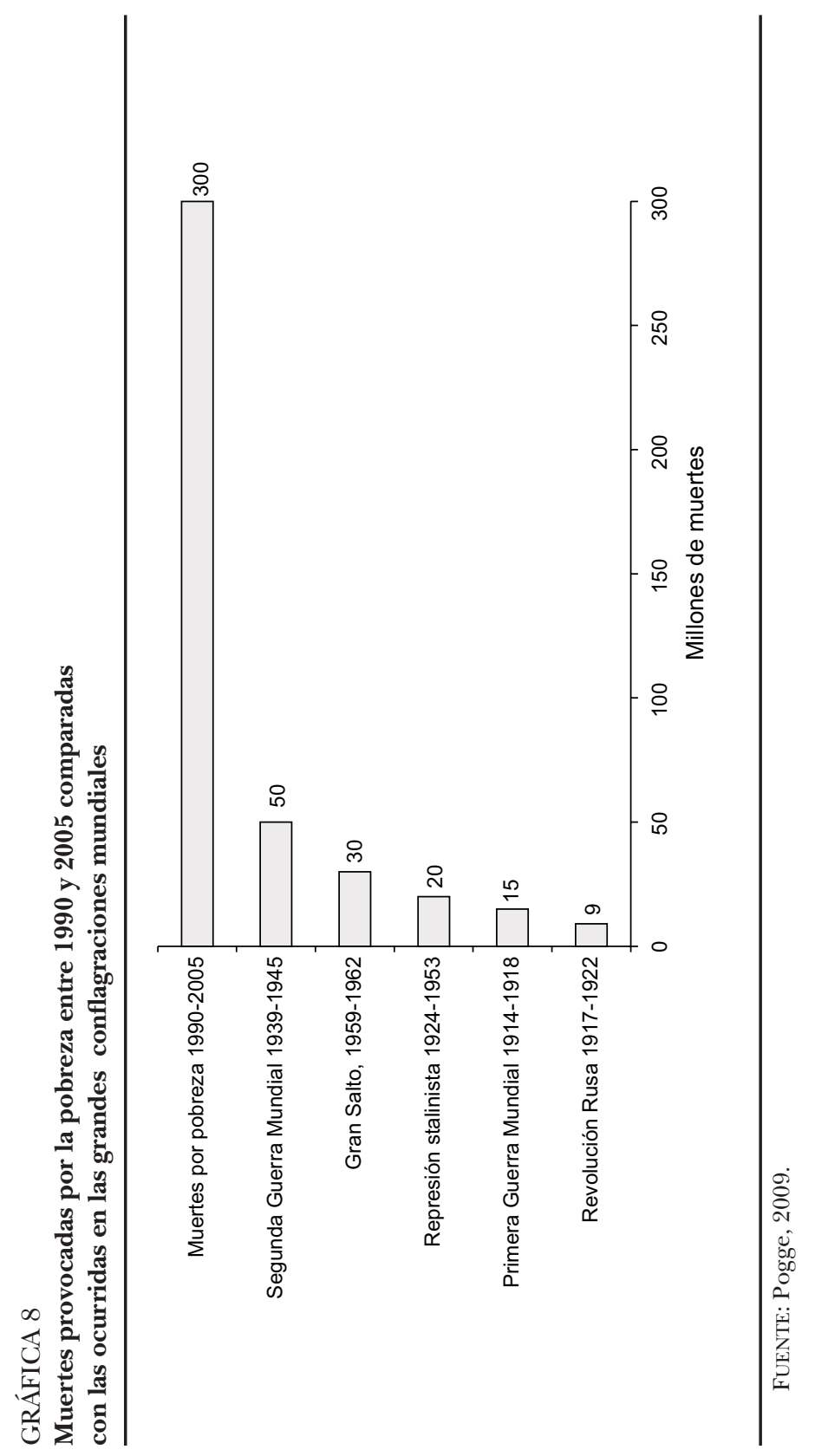


hambre, la mitad de la población de los países industrializados sufre sobrepeso y desperdicia hasta $25 \%$ de la comida (Oxfam, 2011), situación similar a la que se vive en México, como veremos más adelante.

Las muertes por hambre se agudizan en periodos de crisis y alzas en los precios de los alimentos. La FAO (Organización de las Naciones Unidas para la Alimentación y la Agricultura) estimó que el número de personas con hambre en el mundo creció en más de 50 millones como consecuencia del aumento de los precios internacionales de los alimentos ocurrido en 2006, cuyos efectos se prolongaron hasta 2010. ${ }^{30}$

Se ha argumentado que los precios de los alimentos han tenido una tendencia a crecer de manera desproporcionada en relación con los del resto de los productos que se comercializan en el mercado debido a factores tales como: la dependencia para su producción de los bienes derivados del petróleo (fertilizantes, pesticidas, combustibles para maquinaria agrícola, etc.) y el aumento en el precio de ese bien ocurrido en los últimos años; la inestabilidad climática provocada por el calentamiento global; el cambio en los patrones de consumo en los países con más población y desarrollo económico reciente (China, India, etc.); pero sobre todo, la especulación con los alimentos en los mercados financieros de futuros. ${ }^{31}$ La mano "invisible" del mercado ha provocado que la especulación financiera con los alimentos desemboque en un mayor número de personas que padece hambre.

La ineficacia del mercado para subsanar los problemas del hambre también se manifiesta cuando se declara una tragedia humanitaria. La ayuda internacional tarda hasta siete meses en llegar a los lugares afectados, y quienes reciben la mayor proporción de los beneficios otorgados son las empresas de los países donantes (Oxfam, 2011). ${ }^{32}$

${ }^{30}<$ http://www.fao.org/newsroom/es/news/2008/1000866> (consulta: enero de 2014).

${ }^{31}$ En dichos mercados el precio futuro de los alimentos se estima con base en pronósticos de una productividad y abasto a la baja, debido a la escasez de agua y a una posible reducción de la superficie de tierra cultivable en los próximos 40 años (Oxfam, 2011). Otros factores que contribuyen a la reducción de la tierra cultivable son: el aumento de la urbanización, la contaminación y el agotamiento de zonas aptas para el cultivo por la producción intensiva, el uso de pesticidas y los desechos.

${ }_{32}$ Un análisis de Oxfam (2011) sobre la forma como se distribuye el dinero de las donaciones que hacen los países ricos en periodos de hambruna muestra que siete de cada diez pesos de la ayuda otorgada se quedan en su propio territorio. Algo similar sucede con el apoyo económico oficial para el desarrollo que otorgan los organismos internacionales. Aproximadamente $60 \%$ se canaliza a los países receptores por medio de donaciones de los gobiernos ricos a los organismos no gubernamentales internacionales, generalmente constituidos por sus propios ciudadanos o personas ligadas a dichos países, y sólo 40\% se otorga directamente a los países receptores. El monto de las donaciones realizadas por individuos, corporaciones y gobiernos para erradicar la pobreza 
Esta situación quedó evidenciada en Somalia, donde entre 2010 y 2012 fallecieron 260 mil personas por hambre debido a los problemas de sequía, guerra civil y pobreza. La ONU "admitió que su retraso en declarar la situación de hambruna en Somalia en 2011 fue un error que costó más vidas" (La Jornada, 3 de mayo de 2013). Tomando como ejemplo esta tragedia humanitaria de Somalia, es conveniente reflexionar sobre las diferencias en el tipo y la rapidez de respuesta para rescatar empresas y bancos en periodos de crisis por parte de los organismos internacionales y los gobiernos. A raíz de la crisis inmobiliaria de 2008 el gobierno de Estados Unidos implementó un plan de rescate (Troubled Asset Relief Program, TARP) por 700 mil millones de dólares, mediante el cual nueve de los mayores bancos de ese país recibieron del gobierno 125 mil millones de dólares, y 16 bancos regionales más de 33 mil millones de dólares en efectivo a cada uno (La Jornada, 28 octubre de 2008). Compárese estas cifras con el programa de ayuda emergente anunciado por el Banco Mundial para auxiliar a los pobres afectados por la crisis de 2008, cuyo monto fue de tan sólo 189 mil millones de dólares entre 2008 y el cierre del ejercicio de $2011 .{ }^{33}$

Además del hecho de que la comunidad internacional no logra reducir el número de muertes por hambre en el mundo, actualmente se presentan serios problemas de obesidad y diabetes en amplios sectores de la población de bajos ingresos. Ello se debe sobre todo a la transformación en los patrones de consumo, que actualmente incluyen productos industrializados con elevadas cantidades de carbohidratos y azúcares. De acuerdo con Abelardo Ávila (2013), la cantidad de personas afectadas por estos males es tan elevada que la diabetes y la obesidad se han convertido en problemas mundiales de salud pública.

Muchas veces los hogares de bajos ingresos enfrentan una limitada disponibilidad de tiempo para la preparación y el consumo de los alimentos, por lo que buscan formas más rápidas y supuestamente más económicas de satisfacer esta necesidad. La intensa campaña publicitaria llevada a cabo por un pequeño grupo de grandes empresas del ramo alimentario (como MacDonald's, PepsiCo, Coca Cola, Nestlé, entre otras), los lleva a adquirir alimentos con altos contenidos energéticos y grasos, disponibles en sus amplios sistemas de abasto. Ávila (2013) sostiene que estas empresas han creado un "ambiente obesigé-

\footnotetext{
es insignificante, ya que sólo representa $0.05 \%$ del producto interno bruto de los países más ricos (información del PNUD, citada en Pogge, 2005).

$33<$ http://www.bancomundial.org/temas/crisisfinanciera/iniciativas.htm > (consulta: enero de 2014).
} 
nico" mundial, debido a los fuertes intereses económicos que tienen. Por ejemplo, tan sólo en México dichas empresas venden aproximadamente 80 mil millones de dólares al año.

En México la Encuesta Nacional de Nutrición, 2012, encontró que casi $70 \%$ de la población adulta presenta sobrepeso u obesidad, así como alrededor de $30 \%$ de la población en edad escolar (primaria) y adolescentes (véase la gráfica 9). Lo anterior significa que 48 millones de adultos (siete de cada diez) tienen estos padecimientos, y es México el segundo país en el mundo con el índice más alto. Como advierte Ávila (2013), además del problema de salud pública que representa la obesidad en sí misma, conlleva al desarrollo de otros males como la diabetes, la hipertensión, el cáncer de diversos tipos, las cardiopatías y otras enfermedades crónicas, no sólo en los adultos sino en niños y adolescentes, lo que provoca muertes evitables y elevados gastos en salud.

Los efectos destructivos en la salud provocados por los alimentos obesigénicos se presentan de manera más grave entre quienes padecieron desnutrición infantil. De acuerdo con Ávila (2013), en estos casos la probabilidad de padecer diabetes aumenta seis o siete veces en comparación con la del resto de la población, debido a que la falta de consumo energético adecuado para mantener la tasa metabólica basal $^{34}$ en los primeros años de vida provoca daños irreversibles en la plasticidad de las células o de órganos del cuerpo humano (hígado, pulmones, etc.), y por tanto quedan inhabilitados para adaptarse a los cambios en el medio ambiente. Con base en una encuesta levantada por el Instituto Nacional de Ciencias Médicas y Nutrición "Salvador Zubirán”, en 2012 en el Estado de México, Ávila muestra el aumento en la prevalencia de hipertensión arterial y en la resistencia a la insulina en los menores de 12 años obesos. Mientras sólo $13.7 \%$ de los menores de seis a ocho años con peso normal presenta prehipertensión o hipertensión arterial (HTA) alta (grado I y II), entre los obesos el porcentaje aumenta a $42.8 \%$. Para la población de 10 a 12 años de edad con peso normal el porcentaje fue de $25 \%$ y en los obesos de $50.9 \%$. En lo que respecta a la diabetes, los resultados de la encuesta

${ }^{34}$ La tasa metabólica basal es la cantidad de energía que requiere el cuerpo humano para llevar a cabo las funciones de "mantenimiento" físico (comprende actividades básicas del cuerpo humano como la actividad cerebral, la circulación de la sangre, la reparación y reemplazo de células, la digestión, etc.) y representa entre 65 y $80 \%$ de la energía que se consume diariamente. El resto de la energía se utiliza para caminar, hablar, leer, etc. Por ello es fundamental mantener un nivel de ingesta que cubra estos requerimientos desde la gestación y durante la niñez. 


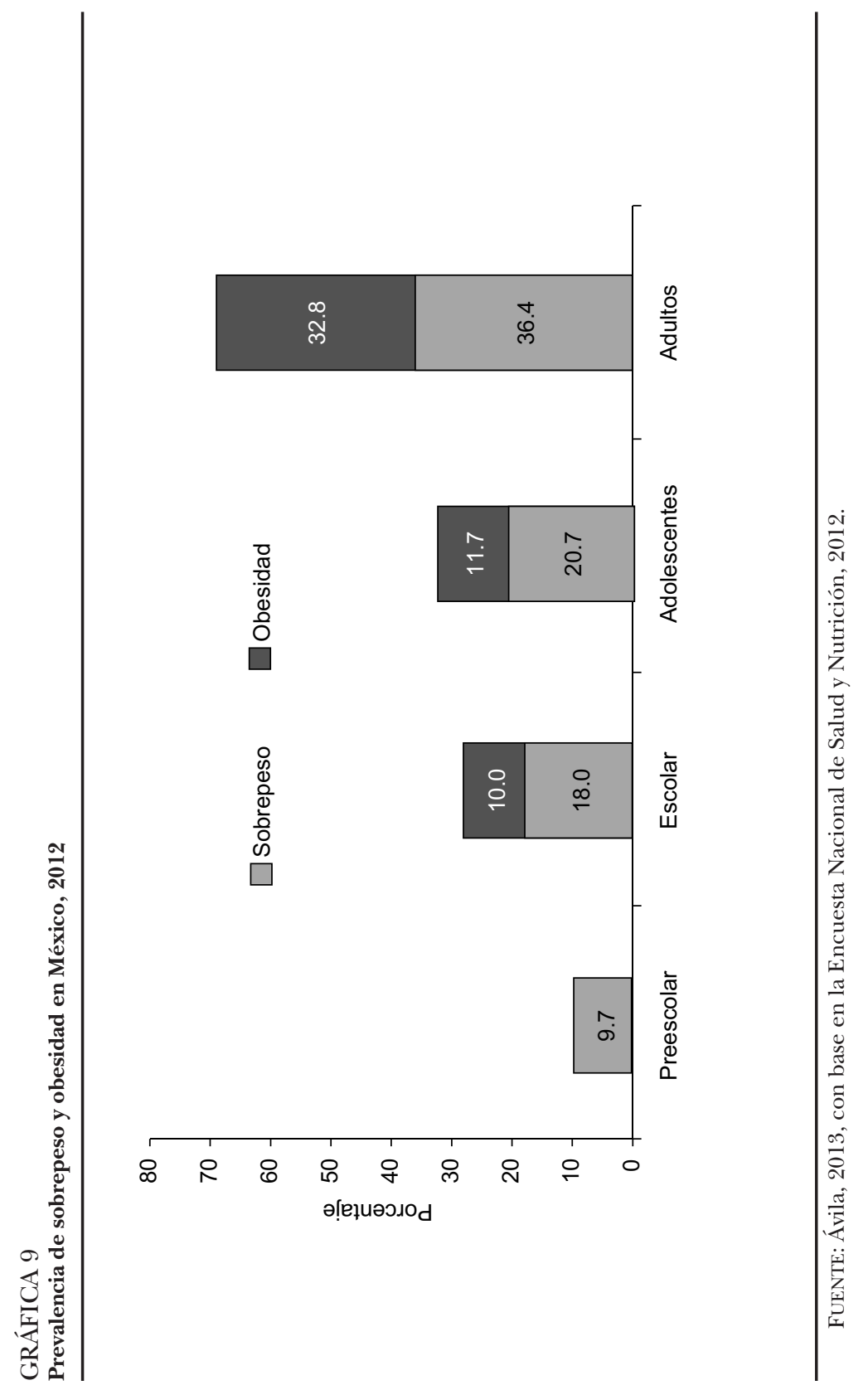


en el Estado de México son alarmantes: en la población de 6 a 8 años con peso normal sólo $6.9 \%$ presenta resistencia a la insulina, comparado con $37.6 \%$ de los menores obesos de esas edades; entre la población de 10 a 12 años los porcentajes que presentan resistencia son de 18.5 y $57.2 \%$, respectivamente. Lo anterior indica que la probabilidad de sobrevivencia de los que tienen resistencia a la insulina será muy baja si llegan a padecer diabetes.

Como Partha Dasgupta (2010) indica, algunas investigaciones recientes han encontrado que los complementos alimenticios de programas sociales también pueden provocar reacciones diabéticas en niños que no están acostumbrados a recibir ingestas elevadas de los carbohidratos y azúcares incluidos en éstos. Además mostraron que los niños tienden a presentar mayores problemas de obesidad, pues dichos complementos contienen grasas en cantidades más altas de las que su cuerpo puede procesar, aun cuando ingieran cantidades que para el promedio de la población parecen ser normales. Dasgupta concluye que los remedios tardíos, como los programas de alimentación enfocados en los menores desnutridos con alimentos "balanceados", pueden causar daños severos a la salud debido a su plasticidad deficiente.

Esta dificultad puede estarse presentando en México en la población beneficiaria del programa Prospera, o bien en la que se incorporó a la llamada "Cruzada contra el Hambre", iniciada por el gobierno federal en 2013. Ávila (2013) pone en duda los posibles logros del programa por no atacar los problemas de obesidad, pero además por no haber seleccionado como beneficiaria a la población de las áreas con mayor grado de desnutrición. Cabe destacar que la "Cruzada" incluyó la participación de las empresas PepsiCo y Nestlé para diseñar y distribuir los productos alimenticios que se usarán en el programa, lo cual constituye una contradicción en tanto que estas empresas son precisamente las que venden los productos que han contribuido a la propagación de la epidemia de obesidad y diabetes en México, y que por tanto tendrían conflictos de intereses al participar en la Cruzada.

Como se observa en la gráfica 10, en el año 2012 los municipios seleccionados (2 457) para la Cruzada (que agrupan 7.4 millones de personas) tienen una prevalencia de sobrepeso y obesidad similar o mayor a la que se presenta en el promedio de la población. Se nota además que el sobrepeso y la obesidad aumentaron drásticamente durante la década de los noventa. Así, mientras que el porcentaje de mujeres adolescentes (de 12 a 19 años de edad) con sobrepeso y obe- 
sidad en 1988 era de $11.1 \%$, en 1999 fue de $27.3 \%$ y en 2012 llegó a $33.4 \%$. Entre las mujeres de 20 a 49 años de edad el sobrepeso y la obesidad pasaron de 24.5 a $61.0 \%$ entre 1988 y 1999, y para 2012 el porcentaje sobrepasó $70 \%$. Ávila puntualiza que desde 1961 el país alcanzó el nivel de consumo calórico promedio requerido que le corresponde al perfil de la población mexicana (2 200 kilocalorías). En ese año el suministro interno de energía fue de 2412 kilocalorías per cápita diarias y desde entonces ha seguido aumentando, llegando a alcanzar 3266 kilocalorías per cápita diarias en 2012, lo que constituye una clara evidencia de la pandemia de obesidad en México. Lo anterior, como hemos visto, no es privativo de nuestro país; constituye una de las manifestaciones de la crisis global que aqueja a nuestra sociedad contemporánea.

\section{Crisis ambiental global}

El cambio climático se manifiesta en el aumento de la frecuencia con la que ocurren los eventos hidrometeorológicos extremos (sequías, inundaciones, heladas, incendios, entre otros). Existe suficiente evidencia para afirmar que esta crisis tiene un origen antropogénico. El resumen sobre cambio climático del Grupo Intergubernamental de Expertos sobre Cambio Climático, 2013 (IPCC, por sus siglas en inglés: Intergovernmental Panel of Climate Change) indica que:

Se ha detectado la influencia humana en el calentamiento de la atmósfera y el océano, en alteraciones en el ciclo global del agua, en reducciones de la cantidad de nieve y hielo, en la elevación media mundial del nivel del mar y en cambios en algunos fenómenos climáticos extremos. Esta evidencia de la influencia humana es mayor desde que se elaborara el Cuarto Informe de Evaluación [2007]. Es sumamente probable que la influencia humana haya sido la causa dominante del calentamiento observado desde mediados del siglo XX [IPCC, 2013: 15].

Aunque los gobiernos, sobre todo de las grandes potencias, reconocen en su discurso esta problemática, su falta de compromiso se manifiesta al constatar el incumplimiento de los acuerdos firmados en el Protocolo de Kioto (1995) en materia de reducción de las emisiones de gases efecto invernadero (GEI). En dicho protocolo se comprometieron a reducir en 5\% las emisiones para el periodo 2008-2012 


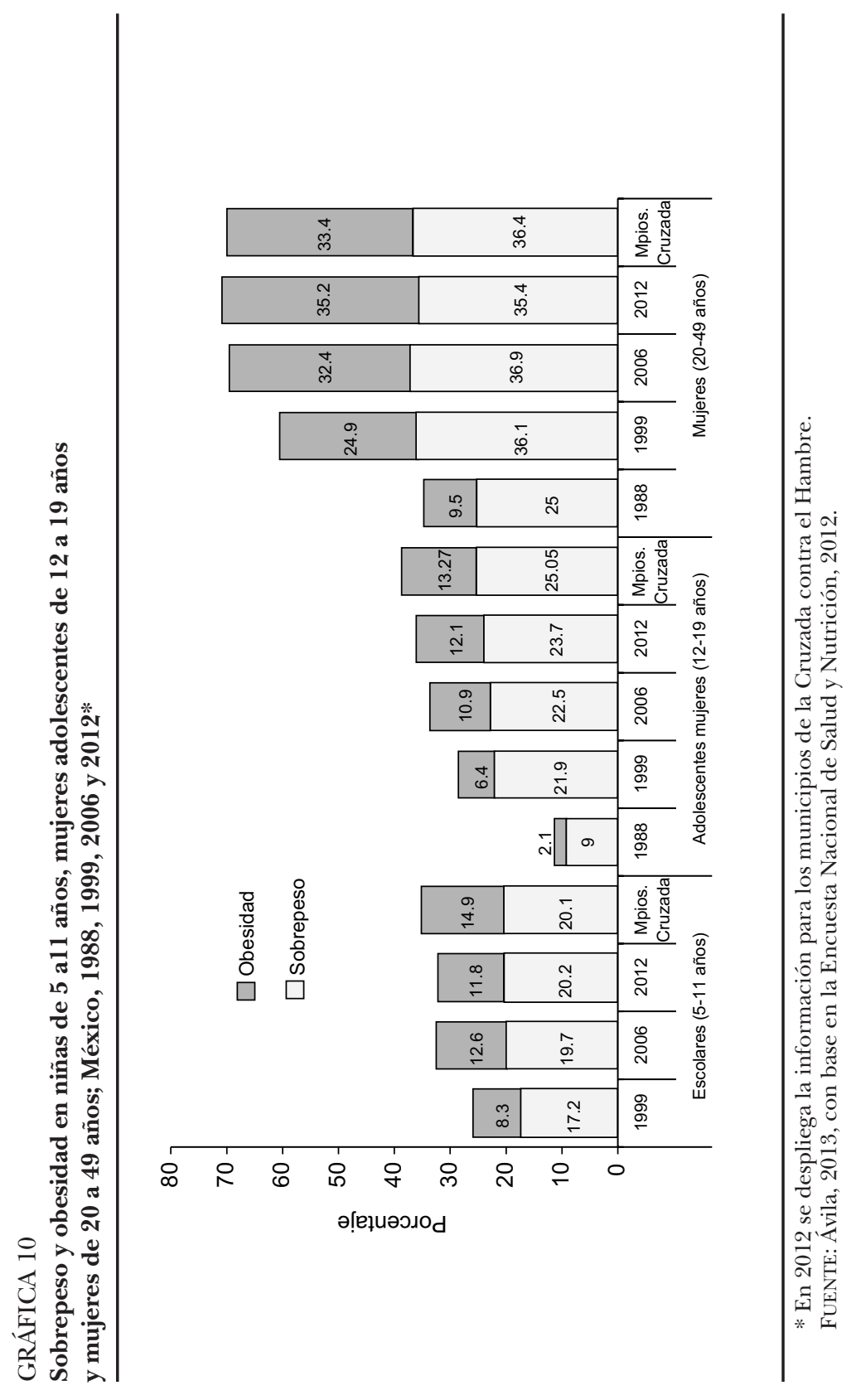


(tomando como año base 1990); sin embargo, de acuerdo con el Cuarto informe de evaluación del Grupo Intergubernamental de Expertos sobre Cambio Climático (IPCC, 2007: 37), entre 1995 y 2005 se presentó la mayor tasa de crecimiento de los GEI respecto de la observada en el periodo 1970-1994; la misma situación se confirma en el informe de 2013.

Según el informe de 2007 los países pertenecientes a la OCDE ${ }^{35}$ fueron los que más contribuyeron al aumento del volumen de las emisiones, con $46 \%$ del total, mientras que las tasas de crecimiento más altas se observaron en China e India. Los gobiernos justifican la falta de cumplimiento de estos acuerdos por el alto costo que según las empresas implicaría modificar la tecnología para lograr tal objetivo. Además, los ciudadanos de países ricos no presionan a sus gobiernos para que tomen medidas efectivas, ya que las muertes asociadas a este fenómeno son relativamente bajas en sus países. De acuerdo con el Anuario 2010 del Programa de Medio Ambiente de las Naciones Unidas (UNEP, por sus siglas en inglés: United Nation Environment Programme), los países ricos están expuestos al 39\% de los ciclones tropicales, pero su población sólo corre con el 1\% de los riesgos mortales asociados a estos fenómenos; en cambio, los países de más bajos ingresos están expuestos a $13 \%$ de esas tormentas y corren con $81 \%$ de los riesgos mortales. De igual forma, se reporta que una revisión de 8866 megadesastres en el mundo encontró que el $0.26 \%$ de esos eventos contribuyó con el $78.2 \%$ de las muertes relacionadas con desastres, todas ellas ocurridas en los países en desarrollo (UNEP, 2010).

Esta crisis ambiental se manifiesta también en la baja de los rendimientos productivos de la agricultura, provocada por el uso intensivo de la tierra y de pesticidas, así como por el agotamiento y los cambios en el ciclo del agua, y la reducción de la tierra cultivable (véase la nota 31). Así, mientras que el crecimiento agregado mundial de los rendimientos fue de $2 \%$ anual durante el periodo 1979-1990, en el de 19902007 bajó a 1\% (Oxfam, 2011). La necesidad de producir en mayor volumen se incrementó recientemente por la utilización de granos para biocombustible (cerca de 15\% de la producción mundial de granos se desvía a este mercado). Esto resulta paradójico si consideramos que un tanque de etanol para automóvil permitiría alimentar a una persona durante todo un año (Lester Brown, citado en Vergopoulos, 2011: 7). Además el Banco Mundial ha advertido que la demanda de biocombus-

${ }^{35}$ Sin considerar para el cálculo a México y a Corea. 
tibles podría aumentar si el precio del petróleo vuelve a repuntar (Banco Mundial, 2012). Asimismo, como resultado del crecimiento del ingreso en los países con elevada población, sobre todo China e India, se observa la occidentalización de la dieta "global", lo que implica una mayor demanda de tierra y de agua para la producción de carne, lo cual a su vez incrementa la cantidad de gases de efecto invernadero.

\section{Ante la crisis: continuidad de los programas de ajuste}

Existen fuertes indicios de que el sistema económico actual tiene serios problemas de realización de las mercancías y colocación del excedente monetario. En los años setenta la crisis global sistémica del capitalismo se manifestó claramente con la caída tendencial de la tasa de ganancia. Los gobiernos de países ricos reaccionaron e impusieron medidas radicales basadas en la teología del libre mercado irrestricto, rechazando así las políticas que sirvieron a la economía mundial en sus años dorados de posguerra.

Las constantes crisis han provocado que numerosas empresas enfrenten la bancarrota, al mismo tiempo que un número impreciso (pero muy elevado) de personas se queda literalmente en la calle o en la pobreza extrema. Los gobiernos han procurado establecer los mecanismos para la defensa de las élites y los grupos económicos nacionales y trasnacionales con mayor poder, rescatando los grandes capitales con ingresos públicos, mientras que otorgan escasos recursos para la población que enfrenta hambre e imponen programas de austeridad que ponen en riesgo el bienestar y la vida de volúmenes importantes de la población.

El cambio de política no tuvo efectos positivos para la mayoría de la población y desde entonces vivimos en constantes crisis económicas: 1979, 1982, 1987, 2000-2001, 2006, 2008-2013. La ineficacia de tales cambios puede deberse, como mencionan Echeverría (2006) y Hobsbawm (1995), al apego irrestricto a los fundamentos de libre mercado. Parafraseando a este último autor, podemos decir que en la crisis de 2008 vivimos una situación similar a la de los años de la Gran Recesión de 1929, y no podemos entender cómo las ortodoxias del libre mercado puro -para entonces tan desacreditadas- vinieron una vez más a imperar; además quienes las impulsan se mantienen a la cabeza de los gobiernos y de los organismos internacionales, y recomiendan profundizar los principios neoliberales.

En el prefacio a la segunda edición de su libro sobre la crisis de los países asiáticos de finales de los noventa, Krugman (2009) escribe que 
en el momento en que dicha edición iba a imprenta, la mayoría de los países del mundo estaban enfrentando una severa crisis financiera. Dice que después de superada la Gran Depresión la mayoría de los economistas pensaba que se habían solucionado los problemas del ciclo económico y que nada similar volvería a pasar. Con optimismo se creía que ningún secretario del Tesoro haría eco de la famosa recomendación de Andrew Mellon, Secretario del Tesoro de Estados Unidos cuando estalló la Gran Depresión, en torno a la medicina requerida para "purgar" lo podrido en el sistema: "liquidar trabajadores, liquidar inventarios, liquidar a los agricultores, liquidar las propiedades". Pero, como observa el autor, los gobiernos y las grandes empresas estaban aplicando en plena crisis mundial de 2009 las mismas recomendaciones, y "como en los años treinta la medicina económica convencional mostró ser inefectiva, tal vez incluso contraproducente" (p. 4).

Si bien las mayores carencias se viven en los países pobres, el incremento de los precios de los alimentos, las recientes crisis inmobiliaria y financiera, y el aumento de la desigualdad están afectando también a los hogares más desfavorecidos de los países ricos.

Ortiz y Cummins (2013) también llegan a una conclusión similar. $\mathrm{Al}$ examinar las recomendaciones de política en 180 países del mundo, a raíz de la crisis de 2009, encuentran que las reformas propuestas por gobiernos y organismos internacionales son similares a las de las otras crisis y que éstas han mostrado que tienden a desacelerar la economía. Para los autores ninguna de dichas políticas ha significado en el pasado un avance importante en el bienestar de la población, y por el contrario, su aplicación tiende a hacer más profundas las crisis en los países menos desarrollados.

De esta forma, encuentran que las reformas propuestas son:

- recortar el gasto público: 3.7\% del PIB en promedio en 65 países en desarrollo, frente a $2.2 \%$ en 26 países de ingreso alto;

- aplicar programas de austeridad que en 2013 afectaron a $80 \%$ de la población mundial (cinco mil millones de personas), que en su mayoría vive en los países menos desarrollados; para 2015 se espera que los programas afecten a $90 \%$ de la población;

- eliminar o reducir los subsidios a gasolinas, agricultura y alimentos (100 países);

- recortar el gasto en salarios, educación, salud y otras áreas del sector público (98 países);

- aplicar mayor racionalidad y focalizar los programas sociales (80 países); 
- reformar el sistema de pensiones (86 países) y el de salud (37 países);

- instrumentar la flexibilidad laboral (32 países);

- ampliar los impuestos al consumo mediante la aplicación del IVA a productos básicos consumidos desproporcionalmente por los hogares pobres (94 países).

Aunque se argumenta que la implementación de esta nueva ola de medidas de ajuste logrará, mediante la contracción fiscal, una mayor capacidad de crecer "sanamente", en realidad tiene el objetivo de aumentar la ganancia vía la reducción de los costos de la mano de obra, la disminución de los beneficios sociales y el aumento de la captación de impuestos al consumo, lo que recaerá sobre todo en los más pobres. Estas medidas afectarán gravemente a la población y agudizarán aún más los problemas de empleo que se padecen actualmente, ya que se recortará el apoyo público en los momentos en que más se necesita.

Los costos del ajuste seguirán siendo cargados por la población más vulnerable y por las clases medias, que de por sí han estado enfrentando reducciones reales en el ingreso por trabajo y han disminuido sus oportunidades de empleo. De esta forma, viviremos en un mundo con precios más elevados en alimentos y combustibles, lo cual es producto de la especulación financiera con materias primas.

Pero las políticas neoliberales son exitosas desde el punto de vista del capital, en tanto que permiten la desvalorización de la fuerza de trabajo; al mismo tiempo se da una mayor concentración monopólica de las empresas productivas y las financieras, y se eleva la riqueza de las élites. Pero, como plantea Bolívar Echeverría (2006: 39), este fundamentalismo de mercado

ha terminado por encaminar a las sociedades transformadas por esta modernidad hacia un abandono desilusionado de aquello que debió haber sido la línea principal del proyecto de la modernidad [...] [que hubiese llevado] a sustituir la actualización religiosa de lo político por una actualización autónoma, es decir, propiamente política, de lo político.

De esta forma, Echeverría reconoce que en esta vuelta de siglo, la migración forzada, el estancamiento económico, el desempleo y la pobreza son por tanto triunfos del libre mercado y no síntomas de su derrota. 


\section{Bibliografía}

Ávila, Abelardo (2013), "El reto de la política social en la agenda pública nacional”, ponencia presentada en el seminario El Reto de la Política Social en la Agenda de Gobierno, México, Universidad Autónoma Metropolitana, 7 de marzo.

Banco Mundial (2012), Monitor de precios de alimentos, Washington, Red de Reducción de la Pobreza y Gestión Económica, 30 de enero.

Boltvinik, Julio (1999), “Anexo metodológico”, en Julio Boltvinik y Enrique Hernández Laos, Pobreza y distribución del ingreso en México, México, Siglo XXI, pp. 313-350.

Boltvinik, Julio (2005), “Ampliar la mirada. Un nuevo enfoque de la pobreza y el florecimiento humano", tesis de doctorado en Ciencias Sociales, México, CIESAS Occidente.

Boltvinik, Julio (2010), "La visión marxista de la crisis y la gran crisis del siglo XXI", en Julio Boltvinik (coord.), Para comprender la crisis capitalista mundial actual, México, Fundación Heberto Castillo.

Boltvinik Julio y Araceli Damián (2003), "Las mediciones de pobreza y los derechos sociales en México", Papeles de Población, nueva época, vol. 9, núm. 35, pp. 101-136.

Boltvinik, Julio y Alejandro Marín (2003), "La canasta normativa de satisfactores esenciales de la Coplamar. Génesis y desarrollos recientes”, Comercio Exterior, vol. 53, núm. 5, pp. 473-484.

Bureau of Labor Statistics (varios años), "Databases, Tables and Calculators by Subject”, Washington, United States Department of Labor $<$ http:/ / data. bls.gov/timeseries/LNS14000000> (consulta: enero de 2014).

Capgemini y Merrill Lynch Wealth Management (2011), World Wealth Report, 2011, París, Bank of America, marzo.

Chen, Shaohua y Martin Ravallion (2008), "The Developing World Is Poorer than We Thought, but No Less Successful in Fight against Poverty", Policy Research Working Paper, núm. 4703, Washington, Banco Mundial.

Damián, Araceli (2002), Cargando el ajuste: los pobres y el mercado de trabajo en México, México, El Colegio de México.

Damián, Araceli (2010a), "Los enredos del Coneval”, ElFinanciero, 8 de febrero.

Damián, Araceli (2010b), "Suspicacia ante el nivel de pobreza", El Financiero, 22 de febrero.

Damián, Araceli (2010c), "La pobreza educativa del Coneval”, El Financiero, 8 de marzo.

Damián, Araceli (2010d), "La mezquindad del Coneval", El Financiero, 22 de marzo.

Dasgupta, Partha (2010), Conferencia dictada en el Brooks World Poverty Institute de la Universidad de Manchester, Inglaterra.

Doyal, Len y Ian Gough (1991), A Theory of Human Need, Londres, MacMillan. 
Echeverría, Bolívar (2006), Vuelta de siglo, México, Era.

Gordon, David (2004), "La medición internacional de la pobreza y las políticas para combatirlas" en Julio Boltvinik y Araceli Damián (coords.), La pobreza en México y el mundo. Realidades y desafíos, México, Siglo XXI, pp. $45-75$.

Guillén, Arturo (2008), "Crisis inmobiliaria y la recesión global”, ponencia presentada en el coloquio América Latina: Escenarios del Nuevo Siglo, Buenos Aires, Sociedad de Economía Política y Pensamiento Crítico Latinoamericano, 22 al 24 de octubre.

Hobsbawm, Eric (1995), Age of Extremes. The Short Twentieth Century, 1914-1991, Londres, Abacus.

IPCC (Intergovernmental Panel of Climate Change) (2007), Cuarto informe de evaluación del cambio climático, Estocolmo, OMM, PNUMA.

IPCC (Intergovernmental Panel of Climate Change) (2013), Cambio climático 2013. Bases físicas. Resumen para responsables de políticas, Oslo, OMM, PNUMA.

Keynes, John Maynard (2006) [1936], La teoría general de la ocupación, el interés y el dinero, México, Fondo de Cultura Económica.

Krugman, Paul (2009), The Return of Depression Economics and the Crisis of 2008, Nueva York, W.W. Norton and Company.

Krugman, Paul (2013) "Sympathy for the Luddites", New York Times <www. nytimes.com/2013/06/14/opinion/krugman-sympathy-for-the-luddites. html?_r=1\&> (13 de junio de 2013).

Moreno, Laura (2011), “¿Colonialismo agrario? Compra de tierras en África”, The Blue Report, núm. 20.

Ortiz, Etelberto (2012), "Los nuevos escenarios de la crisis por una salida social", en Enrique de la Garza Toledo (coord.), La situación del trabajo en México, 2012. El trabajo en la crisis, México, Universidad Autónoma Metropolitana, Iztapalapa / Plaza y Valdés, pp. 15-38.

Ortiz, Isabel y Mathew Cummins (2013), "The Age of Austerity: A Review of Public Expenditures and Adjustment Measures in 181 Countries”, documento de trabajo, Nueva York-Ginebra, Initiative for Policy Dialogue and the South Centre, marzo.

Oxfam (2011), Cultivar un futuro mejor. Justicia alimentaria en un mundo con recursos limitados, Oxford, Oxfam Internacional.

Patel, Raj (2009), The Value of Nothing: How to Reshape Martket Society and Redefine Democracy, Nueva York, Picador.

Pogge, Thomas (2005), "Recognized and Violated by International Law: The Human Rights of the Global Poor", conferencia dictada en el Instituto de Investigaciones Filosóficas de la UNAM, noviembre.

Pogge, Thomas (2009), "Reconocidos y violados por el derecho internacional, los derechos humanos de los pobres globales”, en Thomas Pogge (coord.), Hacer justicia, México, Instituto de Investigaciones Filosóficas, UNAM.

Pogge, Thomas y Sanya Reddy (2009), "La gran incógnita: magnitud, distribu- 
ción y tendencia de la pobreza global”, en Thomas Pogge (coord.), Hacer justicia, México, Instituto de Investigaciones Filosóficas, UNAM, pp. 227-249.

Presidencia de la República (2011), “Anexo estadístico”, Quinto informe de gobierno, México, Presidencia de la República

PNUD (Programa de Naciones Unidas para el Desarrollo) (1997), Informe de desarrollo humano, 1997, Nueva York, Oxford University Press.

Ravallion, Martin (2008), "Which Poverty Line? A Response to Reddy", One Pager, núm. 53, Brasilia, International Poverty Centre, UNDP.

Raventós, Sergi (2012) "Los causantes y algunos gestores políticos de la crisis son en buena parte responsables de los suicidios derivados de la misma", entrevista, Sin Permiso, 3 de junio <http:/ /www.sinpermiso.info/textos/ index.php?id=5004> (consulta: enero de 2014).

Sen, Amartya (2000), "Prólogo", en Peter Svedberg (coord.), Poverty and Undernutrition, Wider, Oxford University Press.

Strachey, John (1939), La naturaleza de las crisis capitalistas, México, Fondo de Cultura Económica.

UNEP (2010), Year Book 2010, New Science and Developments in our Changing Environment, Nairobi, United Nation Environment Programme.

Vergopoulos, Kostas (2011), "La crisis alimenticia: la tierra tiembla", Mundo Siglo XXI, vol. 7, núm. 26, pp. 5-9.

Zúñiga, Juan Antonio (2011), "Se duplicó el déficit comercial agropecuario: Banco de México", La Jornada, 30 de diciembre, p. 17.

Zúñiga, Juan Antonio (2012), "En 11 años de panismo se gastaron más de 87 mil mdd para importar alimentos”, La Jornada, 20 de febrero, p. 27.

\section{Acerca de la autora}

Araceli Damián es profesora investigadora del Centro de Estudios Demográficos, Urbanos y Ambientales de El Colegio de México; ha sido profesora visitante de la Universidad de Bristol y de la Escuela de Medio Ambiente y Desarrollo de la Universidad de Manchester. Es doctora en Economía Urbana por la Universidad de Londres, y es miembro del Sistema Nacional de Investigadores, nivel II. Fue colaboradora del periódico El Financiero entre 2003 y 2013 y obtuvo el Premio Nacional de Periodismo “Antonio Sáenz de Miera”, 2004, en la categoría de artículo de fondo. Tiene diversas publicaciones sobre temas de pobreza y política económica y social. Sus investigaciones y reflexiones sobre la pobreza de tiempo y el uso de este recurso en los hogares la han colocado como referente internacional en dicho tema. Entre sus publicaciones destacan el libro Adjustment, Poverty, and Labour Mar- 
Damián, CRISIS GLOBAL, ECONÓMICA, SOCIAL Y AMBIENTAL

ket in Mexico, Cambridge, Ashgate, 2000; el de Pobreza en México y el mundo. Realidades y desafios, coeditado con Julio Boltvinik y que se encuentra en su cuarta edición (Siglo XXI, 2004). Su más reciente obra se titula El tiempo, la dimensión olvidada en los estudios de pobreza y bienestar, El Colegio de México, 2014. Véase <www.araceli.damian.org>. 
